\title{
X-ray and ion irradiation effects on azurite, malachite and alizarin pictorial models
}

\author{
E. Carrasco*, M. Oujja, M. Sanz, J. F. Marco, and M. Castillejo \\ Instituto de Química Física Rocasolano (IQFR-CSIC), Serrano 119, 28006 Madrid, Spain \\ *Present address: IMDEA Nanoscience, 28049 Madrid (Spain)
}

\section{ABSTRACT}

The analysis by intense radiation sources of painting materials used in artworks gives valuable information about their composition and state of conservation, but it can also induce undesired modifications on the studied substrates. Here we use X-ray photoelectron spectroscopy (XPS) to follow the surface chemical changes that prolonged irradiation with soft $X$-rays (with maximum doses ranging from $\sim 1.2 \times 10^{17}$ to $\sim 3.4 \times 10^{17}$ photons $\mathrm{cm}^{-2}$ ) produce on azurite, malachite and alizarin pigments and on two egg-yolk temperas containing azurite or alizarin. The effects following exposure to Argon ion irradiation have been also studied for malachite and azurite tempera. XPS spectra of the samples show that both types of radiation induce similar superficial alterations, although, at the selected experimental conditions, the modification rate is slower for exposure to soft X-rays. The highest radiation stability is shown for alizarin and, on the contrary, azurite and malachite experience a progressive chemical reduction of $\mathrm{Cu}^{2+}$ to $\mathrm{Cu}^{+}$. The reduction of copper takes also place in the azurite tempera, while the proteins and lipids of the egg-yolk binder of azurite and alizarin temperas are subjected to degradation by irradiation with photons and ions. By employing XPS, the cleavage of C-N, C$\mathrm{O}(\mathrm{H})$ and $\mathrm{C}=\mathrm{O}$ bonds has been identified in the egg-yolk temperas.

\section{Keywords}

X-ray photoelectron spectroscopy (XPS); Radiation side effects; Cultural Heritage; Pigments; Egg-yolk tempera; Degradation of painting materials

\section{Introduction}

The observation of beam-induced changes during the characterization of cultural heritage materials by intense radiation sources (synchrotron radiation, ion and laser beams) has revealed the necessity of studying radiation damage mechanisms and has encouraged the development of mitigation strategies [1]. Both issues are relevant for the analysis of paintings, given the known sensitivity of pigments and painting materials to irradiation by proton induced X-ray emission (PIXE) [2 and references therein], by synchrotron X-rays [3] or by lasers [4-7]. The assessment of damage of Prussian blue $\left(\mathrm{Fe}_{4}\left[\mathrm{Fe}(\mathrm{CN})_{6}\right]_{3} \cdot \mathrm{XH}_{2} \mathrm{O}\right)$ and zinc white $(\mathrm{ZnO})$ pigments following irradiation by synchrotron X-rays $[3,8]$, and of lead white pigments by protons in PIXE [2,9], exemplify a recent approach oriented towards the analysis of radiationinduced side effects in pictorial pigments, their recording for future studies, as well as the minimization of their impact. In the case of lead white pigments $\left(2 \mathrm{PbCO}_{3} \cdot \mathrm{Pb}(\mathrm{OH})_{2}\right)$, structural and chemical modifications induced by PIXE have been identified, and these include dehydration and, under high irradiation dose and current, the transformation of the original lead carbonate to lead oxide [2,9]. Apart from controlling the irradiation conditions, and 
considering the physical and chemical characteristics of the pigment, the full paint complexity seems to determine the irradiation impact. The photoreduction of Prussian blue was shown to be dependent on the interactions with the surrounding materials. The photosensitivity was higher when Prussian blue was mixed with zinc white and diluted or constituted by particles of small size [3]. Furthermore, the degradation of the cellulosic fibre substrate, where the paint was applied [8], seems to produce ambient conditions that trigger the reduction of the pigment, suggesting that the mitigation strategies should be targeted on the substrate (especially if the latter is organic). On the other side, the possibility of early detection of irradiation-induced alterations of painting materials is advantageous for the development of mitigation strategies and a surface-sensitive technique can be suitable for this purpose. X-ray photoelectron spectroscopy (XPS) can provide the elemental composition, chemical state and electronic state of the elements present within the uppermost 1-10 $\mathrm{nm}$ of a substrate. This analytical technique has been employed occasionally to identify aging effects of pigments used in artworks, as well as to study the degradation induced by irradiation with X-rays, protons and laser photons [9-13]. The main objective of the present work is to apply the XPS technique to the analysis of a selection of traditional painting materials in order to determine experimental conditions that minimize the impact of exposure to radiation, and to evaluate the first indications of induced radiation damage which might be of practical interest for the analysts and researchers working in the field of cultural heritage. Supplementary characterization by selected analytical techniques (as proposed explicitly in the following sections) is considered very valuable but lies beyond the scope of the present study. The study has focussed on a representative selection of pigments, of inorganic nature as azurite, malachite, and organic as alizarin. These pigments with three different primary colours of blue, green and red respectively have been commonly employed in the traditional painting practice.

In this study, XPS is used to characterize pure malachite, azurite and alizarin pigments and their egg yolk temperas, as well as to follow as a function of the irradiation time, the induced chemical modifications by prolonged exposure to soft $\mathrm{X}$-rays (with maximum doses ranging from $\sim 1.2 \times 10^{17}$ to $\sim 3.4 \times 10^{17}$ photons $\mathrm{cm}^{-2}$ ) coming from the same source of the analytical equipment.

In addition, this technique is employed to detect the immediate chemical alterations in the copper based pigments and temperas produced by successive exposures to an Ar ion source. A comparison of the irradiation effects induced by photons and ions is also provided. The work is focused on the assessment of alterations at the early stages of damage following irradiation, before a surface modification is observed by visual inspection. This study has obtained further insight into the initial chemical processes of degradation, through the identification of specific chemical functional groups that are prone to alteration following irradiation of painting materials.

\section{Material and methods}

\subsection{Samples}

The irradiation study was performed on pure azurite $\left(2 \mathrm{CuCO}_{3} \cdot \mathrm{Cu}(\mathrm{OH})_{2}\right.$, Kremer), malachite $\left(\mathrm{CuCO}_{3} \cdot \mathrm{Cu}(\mathrm{OH})_{2}\right.$, Aldrich) and alizarin (1,2-dihydroxyanthraquinone, $\mathrm{C}_{14} \mathrm{H}_{8} \mathrm{O}_{4}$, Acros Organics) pigments and on azurite and alizarin tempera paint mock-ups, where the pigments were mixed 
with egg yolk and applied on primed panels. The selection of pigments is motivated by the fact that they are very often used in the traditional painting practice and because they constitute representative examples of pigments of inorganic and organic origin with three different primary colours of blue, green and red, while the tempera samples constitute a realistic reconstruction of traditional unvarnished paintings. The procedure of preparation of the tempera samples was described elsewhere [4]. The tempera mixtures were prepared by a qualified paint restorer following the traditional artist's recipes for tempera paints reported in [14]. The pigment was mixed with the fluid egg binder in proportions that produced a paintable paste and an adequate colour from the restorer's perspective. The tempera mockups were subjected to natural aging for fifteen years in the dark at ambient conditions (around $295 \mathrm{~K}$ and 50\% R.H.) before the present study. Aged paint models have been used since it is commonly considered that, regarding the irradiation damage effects, they simulate better than a freshly prepared one the case of an historical painting.

Small rectangular samples of approximately $10 \times 10 \mathrm{~mm}^{2}$ were cut from the panels. The pure pigments in powder form were pressed into pellets of $12 \mathrm{~mm}$ diameter at $8 \mathrm{ton} \cdot \mathrm{cm}^{-2}$. All the samples, with a thickness of $1.5 \mathrm{~mm}$ (or less), were fixed to metallic sample holders for XPS measurements by double-sided adhesive graphite tape.

\subsection{Analytical Techniques}

X-ray photoelectron spectra were acquired in two different spectrometers: a Leybold LHS-10 XPS with a CLAM2 analyser operated under a vacuum better than $2 \times 10^{-8}$ mbar and a Specs XPS equipped with a hemispherical Phoibos 150 analyser operated under a base pressure of $8 \times 10^{-10}$ mbar. All the spectra were recorded at a take-off angle of $90^{\circ}$ using $\mathrm{Mg}$ Ka radiation (1253.6 $\mathrm{eV}$ ) at $135 \mathrm{~W}$. The step energy was $1 \mathrm{eV}$ for survey scans and $0.1 \mathrm{eV}$ for high resolution ones. The constant analyser pass energy for high-resolution scans was $50 \mathrm{eV}$ in the CLAM2 analyser and $20 \mathrm{eV}$ in the Phoibos 150 analyser, and 200 and $100 \mathrm{eV}$ respectively for wide scans. The binding energy ( $\mathrm{BE}$ ) values were charged-corrected to the adventitious $C$ 1s signal, which was set at $284.6 \mathrm{eV}$. High-resolution spectra were fitted with pseudo Voight line profiles after combined Shirley-linear or Shirley background subtraction (depending on the analysed region) using the CasaXPS software (version 2.3.16). The Lorentzian/Gaussian mixing ratio and FWHM were fixed at the same value along the series of spectra. The quantification of Specs XPS data includes the transmission function correction, the escape depth compensation and the relative sensitivity factors (CasaXPS RSF library) according to the spectral evaluation procedure of the selected software. Quantification of Leybold XPS data uses the relative sensitivity factors from Wagner et al. [15].

The X-ray irradiation alterations in each sample were assessed by recording successive highresolution spectra on the same spot. The continuous exposure to $X$-rays of each sample varies between 24 and 59 hours. The X-ray beam irradiates an area of about $1.5 \mathrm{~cm}^{2}$, as measured by the beam spot size on a phosphor sample. The distance of the sample to the X-ray gun is approximately $4 \mathrm{~cm}$ in the Specs system (due to the sample holder block size) and $2.5 \mathrm{~cm}$ in the Leybold XPS system. The flux of Mg Ka X-rays reaching the samples has been estimated by comparison with the work of Pepper and Wheeler [16] and having into account the attenuation by the $2 \mu \mathrm{m}$ thick Al window. The obtained values are $\sim 1.2 \times 10^{12}$ photons $\mathrm{cm}^{-2} \mathrm{~s}^{-1}$ for the Specs equipment and $\sim 3.4 \times 10^{12}$ photons $\mathrm{cm}^{-2} \mathrm{~s}^{-1}$, for the Leybold XPS system. For the 
copper pigments, the X-ray irradiation studies were performed at the same power conditions $(135 \mathrm{~W})$, both in the Leybold set-up and at the Specs XPS chamber. Following X-ray exposure, the observed spectral changes were equivalent in both set-ups, allowing the generalization of the obtained results. In turn, alizarin pigment and tempera were analysed in the Leybold XPS system.

Additional $\mathrm{Ar}^{+}$bombardment experiments at $1 \mathrm{keV}$, followed by XPS characterization, were performed in the analysis chamber where the Specs XPS system is installed. The ion current was set to $10 \mathrm{~mA}$ for the malachite pigment and to $1 \mathrm{~mA}$ for the azurite tempera. The focused ion beam was raster scanned over the sample surface for a total bombardment time of 60 minutes for each sample, applied in short treatments of 5 or 10 minutes duration. After each short treatment interval, XPS spectra were immediately acquired to follow the induced modifications. The results presented in the next section concerning the copper-based pigments, azurite and malachite, display the spectra acquired in the same Specs XPS chamber, for better comparison of the effects induced on the studied samples following irradiation with both X-rays and Ar ions. The total acquisition time for each spectrum (see Table 1) was selected to avoid changes during and among accumulated scans, while trying to get the optimum signal-to-noise ratio.

\section{Results and discussion}

\subsection{Azurite and malachite pigments}

Fig. 1 shows the effects of X-ray irradiation on the $\mathrm{Cu} 2 p$ core level XPS spectra of azurite $\left(2 \mathrm{CuCO}_{3} \cdot \mathrm{Cu}(\mathrm{OH})_{2}\right)$ at different exposure times up to nearly 56 hours and a dose of $2.4 \times 10^{17}$ photons $\mathrm{cm}^{-2}$. For clarity, the spectra are presented vertically displaced. At short exposure times, the $\mathrm{Cu} 2 \mathrm{p}_{3 / 2}$ and $\mathrm{Cu} 2 \mathrm{p}_{1 / 2}$ peaks are located at $934.6 \mathrm{eV}$ and $954.4 \mathrm{eV}$, respectively, and two intense shake-up satellites are observed at $\sim 944 \mathrm{eV}$ and $\sim 962 \mathrm{eV}$. All these features are characteristic of $\mathrm{Cu}^{2+}[17]$. By increasing irradiation times, $\mathrm{Cu} 2 \mathrm{p}$ main peaks are broadened, their maxima shifted to lower binding energies and the intensity of the satellites decreased, being indications of $\mathrm{Cu}^{2+}$ reduction by $\mathrm{X}$-ray exposure. In fact, by fitting the $\mathrm{Cu} 2 \mathrm{p}_{3 / 2}$ spectra, a narrow component at $932.4 \mathrm{eV}$ is present, which is assigned to $\mathrm{Cu}^{+}$[18]. The continuous increase with time of the $\mathrm{Cu}^{+}$peak indicates a progressive reduction of the azurite pigment under X-ray irradiation (see Table 2 ) and the formation of cuprite $\left(\mathrm{Cu}_{2} \mathrm{O}\right)$. Apart from $\mathrm{Cu}_{2} \mathrm{O}$, there exists another metastable copper oxide, $\mathrm{Cu}_{4} \mathrm{O}_{3}$, containing both $\mathrm{Cu}^{+}$and $\mathrm{Cu}^{2+}$ ions. This scarce mineral can also be synthesized in particular conditions and formed from $\mathrm{CuO}$ nanoparticles in mild reducing conditions. However, its presence is not expected in vacuum [19] and therefore, we assign the detected new $\mathrm{Cu}^{+}$peak only to $\mathrm{Cu}_{2} \mathrm{O}$.

Modifications induced by X-ray irradiation are not restricted to the $\mathrm{Cu} 2 \mathrm{p}$ spectra but also observed in the $\mathrm{C} 1 \mathrm{~s}$ (Fig. 2a) and $\mathrm{O} 1 \mathrm{~s}$ (Fig. 2b) regions. The $\mathrm{C}$ 1s spectra can be deconvoluted into four components at $284.6 \mathrm{eV}$ (C-C), $286.3 \mathrm{eV}$ (C-OH), $287.7 \mathrm{eV}$ (C=O, O-C-O) and $289.1 \mathrm{eV}$ $\left(\mathrm{CO}_{3}\right)$ [20]. The first three components are due to carbon contamination (mainly adventitious carbon at $284.6 \mathrm{eV}$ and in lesser extent, organic compounds) commonly present in samples exposed to ambient conditions. The last component, at the highest binding energy (BE), is characteristic of carbonates. The fitting of the $O 1 \mathrm{~s}$ spectra displays a main component at $531.4 \mathrm{eV}$, which can be attributed to hydroxides/carbonates. The peak at $529.9 \mathrm{eV}$ is assigned 
to $\mathrm{Cu}_{2} \mathrm{O}$ [21]. The component at $532.9 \mathrm{eV}$ can be assigned to adsorbed molecular water [21], but a contribution from an organic compound, related to the $\mathrm{C}$ component at $286.3 \mathrm{eV}$, cannot be discarded. Table 2 displays the most relevant quantitative data obtained from the ratios of the areas of the aforementioned components. The continuous increase of $\mathrm{Cu}^{+} / \mathrm{Cu}^{2+}$ and $\mathrm{O}_{529.9} /$ $\left(\mathrm{O}_{532.9}+\mathrm{O}_{531.4}\right)$ ratios with exposure to irradiation indicates a surface enrichment in cuprite. In azurite, the progressive decrease of the ratios of the areas of $\mathrm{O}_{531.4}, \mathrm{O}_{532.9}$ and $\mathrm{C}_{289.1}$ components with respect to their initial value (signalled with a 0 superscript in Table 2 ) reflects a moderate dehydration (loss of $\mathrm{H}_{2} \mathrm{O}$ ), dehydroxylation (loss of $\mathrm{OH}$ ) and decarbonation. On the other side, it is relevant to mention that vacuum can be considered as a reducing environment. In order to discriminate the effect of vacuum in the observed copper reduction effect, XPS spectra of the copper pigments were acquired after continuous X-ray irradiation, for approximately 12 hours, and after the same time interval in vacuum, having the X-rays gun off. The slight broadening in the shape of the main peak of $\mathrm{Cu} 2 \mathrm{p}$ in the latter case was negligible in comparison with the irradiation-induced effects.

Prolonged X-ray irradiation of malachite $\left(\mathrm{CuCO}_{3} \cdot \mathrm{Cu}(\mathrm{OH})_{2}\right)$ with doses up to $2.6 \times 10^{17}$ photons $\mathrm{cm}^{-2}$ induces spectral changes equivalent to azurite as displayed in Fig. 3a. Reduction of $\mathrm{Cu}^{2+}$ to $\mathrm{Cu}^{+}$in azurite and malachite upon X-ray irradiation is in agreement with the results obtained after X-ray exposure of several other copper compounds, such as $\mathrm{CuO}[22,23], \mathrm{Cu}(\mathrm{OH})_{2}[21], \mathrm{Cu}$ oxalate [24] and $\mathrm{CU}(\mathrm{II})$ complexes [25], and with the photoreduction effect of $\mathrm{CuO}$ after irradiation with a mercury lamp $(253.7 \mathrm{~nm})$ [26]. The effect of nanosecond Q-switched Nd:YAG laser irradiation of malachite at ambient conditions was studied at the wavelength of 1064 and decomposition of the pigment in $\mathrm{CuO}$ and/or $\mathrm{Cu}_{2} \mathrm{O}[11,27]$ was identified. Also for malachite, and using three different Nd:YAG laser wavelengths (213, 248 and $1064 \mathrm{~nm}$ ) and pulse durations ( $15 \mathrm{~ns}, 150 \mathrm{ps}$ and $500 \mathrm{fs}$ ), Oujja et al. [12] observed by XPS the formation of $\mathrm{Cu}^{+}$by reduction of $\mathrm{Cu}^{2+}$ at all excitation conditions explored. Additionally, in this case, the microRaman spectra of the samples after laser irradiation revealed the appearance of a new band at $640 \mathrm{~cm}^{-1}$ indicative of the presence of $\mathrm{Cu}_{2} \mathrm{O}$. Raman spectroscopy was also employed to observe the in-situ formation of $\mathrm{Cu}_{2} \mathrm{O}$ during bombardment of the malachite pigment with $\mathrm{Xe}$ ions of $628 \mathrm{MeV}$ [28]. All these results suggest that irradiation with both laser photons and particles induce surface modifications of similar chemical character. In fact, low energy ion bombardment ( $\leq 1.5 \mathrm{keV}$ ) is commonly used to purposely modify the surface composition of materials followed by XPS analysis to characterize the treated surfaces. This approach is followed here in order to compare the effects of both types of irradiation, $\mathrm{X}$-rays and $\mathrm{Ar}^{+}$, and to get further insight into the involved processes.

Fig. $3 b$ shows the $\mathrm{Cu} 2 \mathrm{p}, \mathrm{O} 1 \mathrm{~s}$ and $\mathrm{C} 1 \mathrm{~s}$ XPS spectra of malachite after successive $\mathrm{Ar}^{+}$ bombardment treatments. The comparison of Figs. $3 a$ and $3 b$ gives evidence that, under the selected conditions, ion bombardment induces more significant surface modifications than the $X$-rays in a much shorter time scale, although the observed spectral changes present very similar characteristics for both types of treatment. Table 3 displays the most relevant quantitative information obtained from the ratios of the areas of the chemical components and reveals similar tendencies with exposure to irradiation to those shown in Table 2. The area ratios corresponding to $\mathrm{Cu}^{+} / \mathrm{Cu}^{2+}$ and $\mathrm{O}_{529.9} /\left(\mathrm{O}_{532.9}+\mathrm{O}_{531.4}\right)$ increase, whereas the areas of the $\mathrm{O}_{531.4}, \mathrm{O}_{532.9}$ and $\mathrm{C}_{289.1}$ components decrease after prolonged $\mathrm{X}$-ray exposure or consecutive irradiations with $\mathrm{Ar}^{+}$. The higher efficiency of ion bombardment could also be enhanced by the 
substantially lower concentration of carbon-related contaminants of the malachite sample. The appearance of an $\mathrm{O}_{529.9}$ component after 1 hour of $\mathrm{X}$-ray exposure, when no $\mathrm{Cu}^{+}$in malachite is detected yet, is unclear, since no other metal has been detected in the survey spectrum apart from copper.

In azurite and malachite pigments, the increase of the $\mathrm{Cu}^{+}$component takes place concurrently with the decrease of water content and carbonates, suggesting the simultaneous formation of copper oxide and the decomposition of hydroxyl-carbonate under both irradiation sources. These results share similarities with ion bombarded $\mathrm{CuO}$ [29] and $\mathrm{Cu}(\mathrm{OH})_{2}$ [21], where the formation of cuprite in both cases and a decrease in adsorbed water in copper hydroxide has been detected by XPS. Furthermore, after ion or atom bombardment, some metal transition carbonates $\left(\mathrm{NiCO}_{3}, \mathrm{CoCO}_{3}\right.$ and $\left.\mathrm{ZnCO}_{3}\right)$ present newly formed oxide species apart from the residual carbonates, as detected by XPS [30]. On the other side, the thermal stability of azurite and malachite has also been evaluated in several experiments (Frost et al. [31] and references therein). Thermal decomposition of these two pigments in a flowing nitrogen atmosphere [31] occurs in six stages, where loss of water precedes carbonate decomposition at temperatures below $325{ }^{\circ} \mathrm{C}$. Besides, $\mathrm{Cu}_{2} \mathrm{O}$ is formed at the last stage by reduction of $\mathrm{CuO}$ at $840{ }^{\circ} \mathrm{C}$ (after previous decomposition in stage 5 of copper carbonate in $\mathrm{CuO}$ and $\mathrm{CO}_{2}$ ). This separation of processes and formation of some intermediates during the thermal controlled analysis of azurite and malachite seems not to take place at the surface of these pigments upon prolonged X-ray or ion irradiation.

The origin of the above difference must be related to the physicochemical processes involved in the irradiation treatments. During ion bombardment, an energy transfer process from the incoming primary ions to the substrate atoms near the surface is expected to occur via twobody collisions. At $1 \mathrm{keV}$ (linear cascade regime), not only the atoms recoiling from the iontarget collision receive sufficient energy to be sputtered out of the sample, but also the recoil atoms themselves carry enough energy to produce further recoils [32]. A damaging cascade is generated, but the density of recoil atoms is low enough so that knock-on collisions dominate. Lattice defects are produced, primary ions are implanted in the topmost atomic layers and, finally, the surface substrate (or adsorbate) atoms are removed as neutrals or as secondary ions. The resulting sputtering effect produces modifications in the composition and morphology (roughening on the atomic scale) of the sample surface and near surface regions (several $\mathrm{nm}$ in thickness). Besides, a preferential sputtering can take place on multicomponent targets, which depends on the bombarded material and on the experimental conditions. Lightweight components are usually preferentially sputtered if the binding energies are similar to the rest of components. In particular, the creation of oxygen vacancies with a preferential sputtering of oxygen in oxides is common, mainly in transition metal oxides [33]. This phenomenology seems to occur in the present case where the $\mathrm{O}$ and $\mathrm{C}$ content (including hydroxyls and carbon contaminants) decreases in the copper pigments with the corresponding chemical reduction of $\mathrm{Cu}^{2+}$ to $\mathrm{Cu}^{+}$. Regarding X-ray irradiation, the photoabsorption process generates energetic photoelectrons or Auger electrons, which stimulate many secondary ionization events as well as electronic excitations. The emission of (photo- and Auger) electrons into vacuum leads to a positively charge layer, which corresponds to missing electrons (or broken bonds) in this surface region. The transport of the electrons also induces electron/hole pairs, which can lead to antibonding repulsive states. In addition, charge 
accumulation in insulators is also related to damage. The build-up of an electric field can also induce the migration of the mobile ions and alter the composition of the sample [34]. The Auger decay on the first excited atoms leads to the X-ray induced desorption of volatile species situated on the surfaces, and, in the bulk, dissociation [34]. In fact, the observed photoreduction of some metal oxides has been explained by an interionic Auger decay (or Knotek-Feibelman mechanism) [33]. The ejection of photoelectrons from the metal core levels initiates an interatomic Auger process which can lead to the formation of holes in the oxygen valence orbitals (the metal core hole is refilled via an interatomic electron transfer from the valence band of the oxygen atoms). If this process leads to the formation of $\mathrm{O}^{+}$ions, the oxygen atom desorbs due to Coulomb repulsion with the nearest neighbor cations. The combination of all the aforementioned processes resulting from photoabsorption (not necessarily with the same weight) can induce the detected hydroxyl-carbonate decomposition due to the loss of $\mathrm{O}, \mathrm{C}$ and the reduction of $\mathrm{Cu}^{2+}$ to $\mathrm{Cu}^{+}$. As a consequence, similar surface modifications by soft $\mathrm{X}$-rays and ions are produced. As $\mathrm{X}$-rays penetrate deeper (several microns) into the sample than $\mathrm{Ar}^{+}$, the damage density of $\mathrm{X}$-rays is lower. Then, longer exposures at the relatively low photon flux selected are required in order to produce similar surface damage as ions.

\subsection{Alizarin pigment}

$\mathrm{C} 1 \mathrm{~s}$ and $\mathrm{O}$ 1s XPS spectra of alizarin at different X-ray exposure times are displayed in Figs. 4a) and $4 b$ ), respectively. Under prolonged X-ray irradiation, no modifications in shape or intensity with time are apparently detected by visual inspection of both series of spectra. In order to confirm this tendency, a quantitative analysis of the spectra was performed. The $\mathrm{C} 1 \mathrm{~s}$ spectrum is deconvoluted into three main components $284.6 \mathrm{eV}(\mathrm{C}-\mathrm{C}), 286.3 \mathrm{eV}(\mathrm{C}-\mathrm{OH})$ and $287.4 \mathrm{eV}$ (C=O) plus two shake-up satellites at $289.7 \mathrm{eV}$ and $291.5 \mathrm{eV}$ [20], in accordance with the structural formula of alizarin (since alizarin characterization by XPS has not been found in the literature). The small decrease ( $\sim 4 \%$ ) measured for the first 3 hours for the component at $284.6 \mathrm{eV}$ is probably due to desorption of some carbon contamination. No additional modifications with time in the area of each component were detected. Likewise, the $\mathrm{O} 1 \mathrm{~s}$ spectrum was deconvoluted into two main components at $531.4 \mathrm{eV}(\mathrm{C}=\mathrm{O})$ and $533.0 \mathrm{eV}$ (C$\mathrm{OH})$, plus two shake-up satellites at $534.7 \mathrm{eV}$ and $536.9 \mathrm{eV}$. Along the series, the analysis indicates the absence of changes in the area of each component, in agreement with the results obtained for $\mathrm{C} 1 \mathrm{~s}$. Therefore, the alizarin pigment seems to be substantially less sensitive to prolonged X-ray exposure at moderate power than pure azurite and malachite pigments.

\subsection{Alizarin egg tempera}

In the survey spectrum of alizarin tempera (not shown), photoelectron features of the $C 1 \mathrm{~s}, 0$ $1 s, N 1 s, P 2 s, P 2 p, S 2 p, S 2 s$ and Ca $2 p$ components can be identified, together with the $C$ and $\mathrm{O}$ Auger peaks. While $\mathrm{C}, \mathrm{O}, \mathrm{N}$ and $\mathrm{P}$ peaks can be related to the tempera paint composition, the $\mathrm{S}$ and $\mathrm{Ca}$ small peaks could also be attributed to residues of the employed preparation substrate (containing gypsum, $\mathrm{CaSO}_{4} \cdot 2 \mathrm{H}_{2} \mathrm{O}$ ) and to, although not exclusively, the elemental components of egg yolk. As a consequence, the irradiation effects induced by prolonged exposure to $\mathrm{X}$-rays are restricted to the time evolution of the most intense peaks observed in the spectra, i.e., $C 1 s, O$ s and $N$ 1s. Fig. 5 shows $N 1 s, O$ s and $C 1 s$ high resolution XPS 
spectra of alizarin tempera at the indicated X-ray exposure times. Firstly, we can observe that, due to the presence of the binder, $\mathrm{O} 1 \mathrm{~s}$ and, in lesser extent, $\mathrm{C}$ 1s spectra have line-shapes that differ from the ones corresponding to the pure alizarin pigment (Fig. 4). It can be deduced that the $\mathrm{X}$-rays are essentially probing the binder (not necessarily in the same conditions as if the pigment would be absent), although some spectral contribution from the alizarin pigment itself cannot be discarded. Secondly, the photoelectron spectra of alizarin tempera experience progressive modifications under irradiation conditions where the spectra of pure alizarin remain the same.

Although the interpretation of XPS component analysis for alizarin is quite straightforward, based on the pigment structural formula, an equivalent analysis for alizarin egg tempera is much more complex. When dried, egg yolk is constituted by a $62.5 \%$ of lipids, $33 \%$ of proteins, $1.2 \%$ of carbohydrates and $3.5 \%$ of minerals [35]. Egg yolk lipids are associated with lipoprotein assemblies that consist mainly of triglycerides (62\%), phospholipids (33\%), and cholesterol (5\%). Phosphatidylcholine is the main component of egg yolk phospholipids (more than two-thirds). Besides, some degree of chemical interaction between the binding medium (egg yolk) and the pigment is expected to take place. In Fig. 5, the $\mathrm{N} 1 \mathrm{~s}$ spectrum is fitted by two components at $399.7 \mathrm{eV}$ (uncharged nitrogen) and $402.2 \mathrm{eV}$ (positively charged nitrogen). The component at $399.7 \mathrm{eV}$ is characteristic of amine or amide groups, while the component at $402.2 \mathrm{eV}$ is attributed to quaternary ammonium $[20,36]$. This last component at higher BE has been detected by XPS on dipalmitoyl phosphatidylcholine and egg yolk containing samples $[36,37]$, and is indicative of the presence of phospholipids in the tempera paint. The fit of the $C$ $1 \mathrm{~s}$ peak gives rise to four components. The most intense component at $284.6 \mathrm{eV}$ is related to carbon bound to carbon and hydrogen $(\underline{\mathrm{C}}-\mathrm{C}, \underline{\mathrm{C}}-\mathrm{H})$. The second component in intensity at 286.0 $\mathrm{eV}$ is due to carbon singly bound to nitrogen and oxygen ( $\underline{\mathrm{C}}-\mathrm{O}, \underline{\mathrm{C}}-\mathrm{N})$ and is attributed to alcohol, amine or amide groups. The component at $287.5 \mathrm{eV}$ can be associated to (hemi)acetal or amide groups ( $\underline{\mathrm{C}}=\mathrm{O}, \mathrm{O}-\underline{\mathrm{C}}-\mathrm{O}$ ) and the component at $288.8 \mathrm{eV}$ is attributed to carboxyls or esters $(\mathrm{O}=\underline{\mathrm{C}}-\mathrm{OH}, \mathrm{O}=\underline{\mathrm{C}}-\mathrm{OR})[20,36]$. The component analysis of $\mathrm{O}$ 1s is intrinsically difficult, not only because of the aforementioned sulphate and phosphate content in the sample, but also because of the relatively weaker chemical shifts for different oxygen environments [20]. Nevertheless, the $\mathrm{O} 1 \mathrm{~s}$ spectrum can be deconvoluted into three components. The component at $530.9 \mathrm{eV}$ is attributed to oxygen doubly bound to amide, carboxyl and ester ( $\mathrm{N}-\mathrm{C}=\underline{\mathrm{O}}, \underline{\mathrm{O}}=\mathrm{C}-$ $\mathrm{OH}, \underline{\mathrm{O}}=\mathrm{C}-\mathrm{OR}$ ). In addition, this component has contributions of oxygen bound to phosphorous $\left(\mathrm{P}=\underline{\mathrm{O}}, \mathrm{P}_{-}-{ }^{-}\right)$in phosphate groups [38]. The component at $533.2 \mathrm{eV}$ is assigned to oxygen singly bound to carbon in carboxyl and ester $(\mathrm{O}=\mathrm{C}-\underline{\mathrm{O}} \mathrm{H}, \mathrm{O}=\mathrm{C}-\underline{\mathrm{O}} \mathrm{R})$. The main component at $531.9 \mathrm{eV}$ can be related to oxygen forming single bonds with carbon ( $\mathrm{C}-\underline{\mathrm{O}} \mathrm{H}, \mathrm{C}-\underline{\mathrm{O}}-\mathrm{C})$.

Table 4 shows that $\mathrm{N} / \mathrm{C}$ and $\mathrm{O} / \mathrm{C}$ ratios decrease progressively in alizarin tempera during exposure to $\mathrm{X}$-rays up to a maximum dose of $3.4 \times 10^{17}$ photons $\mathrm{cm}^{-2}$. However, not all the components of these regions are reduced at the same rate with time. The $\mathrm{O}_{530.9} / \mathrm{O}_{531.9}$ ratio increases from 0.34 to 0.63 whereas the $\mathrm{O}_{533.2} / \mathrm{O}_{531.9}$ ratio stays around a value of 0.4 during the prolonged irradiation time. Since the peak at $530.9 \mathrm{eV}$ is mainly assigned to $\mathrm{C}=\mathrm{O}$, and the other oxygen components to $\mathrm{C}-\mathrm{O}$, the latter bond seems to be more sensitive to irradiation. The ratios of the carbon bound to oxygen components decrease with respect to $C_{284.6}$. However, the decrease of $C_{287.5} / C_{284.6}$ and $C_{288.5} / C_{284.6}$ ratios is more relevant than the decrease of $\mathrm{C}_{286.0} / \mathrm{C}_{284.6}$ ratio. These results suggest that the carboxyl groups, esters and hemi(acetal) 
groups are more probably affected by prolonged X-ray irradiation than other functional groups containing carbon bonds. In combination with the trends observed in the $\mathrm{O} 1 \mathrm{~s}$ components, cleavage would be more favourable in the $\mathrm{C}$-O bond of these functional groups. $\mathrm{C}_{284.6}$ increases roughly a $5 \%$ in 27 hours and experiences a small broadening (requiring a FWHM increase of nearly $0.2 \mathrm{eV}$ to optimize the analysis of components). This could be indicative of some hydrocarbon fragment deposition or changes in the polymeric network. In the case of $\mathrm{N} 1 \mathrm{~s}$, the progressive decrease of the area ratios of $N_{399.6}$ and $N_{402.2}$ components with respect to their first initial value suggests that phospholipids and egg yolk proteins degrade similarly in the alizarin tempera under the selected irradiation conditions. The present results point towards relevant modifications of the binding medium by prolonged exposure to $\mathrm{X}$-rays in agreement with review articles [1,2]. The observed decrease in the different elemental signals is related to desorption of some molecular fragments after the aforementioned bond scission. This topic will be discussed in the text later on.

Chemical changes after exposure to light or air pollutants $\left(\mathrm{NO}_{x}\right.$ and $\left.\mathrm{SO}_{2}\right)$, such as oxidation of lipids, have been detected in alizarin tempera by different mass spectrometric techniques [39]. The analysis showed that the changes following exposure to ambient light were similar for the unpigmented tempera (whole egg) and for alizarin tempera paint samples, used as dosimeters for environmental monitoring of museum display conditions. The similarity gives an indication of the low degree of interaction of the alizarin pigment with the binder. In addition, the sensitivity of the binder towards light at ambient conditions in alizarin tempera was shown to be clearly higher than the sensitivity of alizarin pigment in the tempera, in line with the present observations.

\subsection{Azurite egg tempera}

The survey spectrum of azurite tempera displays the photoelectron features of $C 1 \mathrm{~s}, 01 \mathrm{~s}, \mathrm{~N}$ $1 \mathrm{~s}, \mathrm{P} 2 \mathrm{~s}, \mathrm{P} 2 \mathrm{p}$ and an almost undetectable $\mathrm{Cu} 2 \mathrm{p}$ signal, together with $\mathrm{C}$ and $\mathrm{O}$ Auger peaks (not shown). In contrast to alizarin tempera, calcium and sulphur seem not to be present in the azurite tempera surface. Fig. 6a displays the high resolution $\mathrm{Cu} 2 \mathrm{p}, \mathrm{N} 1 \mathrm{~s}, \mathrm{O} 1 \mathrm{~s}$ and $\mathrm{C}$ 1s core level XPS spectra of azurite tempera at different X-ray exposure times, while Fig. $6 \mathrm{~b}$ displays the same regions after the indicated ion bombardment time intervals. Table 5 lists the most relevant quantitative changes resulting from the spectral analysis after both types of exposure. Both Fig. 6 and Table 5 reveal that both irradiation sources induce similar modifications in the azurite tempera. The $\mathrm{N} 1 \mathrm{~s} / \mathrm{C} 1 \mathrm{~s}$ and $\mathrm{O} 1 \mathrm{~s} / \mathrm{C} 1 \mathrm{~s}$ ratios in azurite tempera experience an initial increase (after 15 minutes of $\mathrm{Ar}^{+}$irradiation or for the first 7 hours of X-ray irradiation) ascribed to carbon contamination desorption (see evolution of the $\mathrm{C}_{284.6}$ component), and a progressive decrease as irradiation exposure continues. Before ion or prolonged $\mathrm{X}$-ray exposure, the $\mathrm{Cu} 2 \mathrm{p}_{3 / 2}$ spectra in both panels of Fig. 6 display a broad main peak at around 933 $\mathrm{eV}$ and a small shake-up satellite above $940 \mathrm{eV}$. Given the noise in the $\mathrm{Cu} 2 \mathrm{p}_{3 / 2}$ spectra, the component analysis is based on employing the parameters used for $\mathrm{Cu} 2 \mathrm{p}_{3 / 2}$ in the case of azurite pigment (shown in Fig. 1), including the line shapes, the FWHMs and certain constrains in the position of the maxima of the four components. Then, the fitting to the data is done by minimizing the sum of squares residual, where the intensity for a peak is extracted as one of the optimization parameters. As a result, the main peak can be deconvoluted into two components at 934.8 and $932.6 \mathrm{eV}$, due to $\mathrm{Cu}^{2+}$ and $\mathrm{Cu}^{+}$oxidation states, respectively. We can 
observe that the azurite pigment in the egg-yolk tempera is already partially reduced at the beginning of the irradiation period and this reduction effect progresses after subsequent exposure to X-ray photons or Ar ions. The reduction effect induced by irradiation is relevant, since the ratio of $\mathrm{Cu}^{+} / \mathrm{Cu}^{2+}$ increases from 0.38 to 1.35 after 60 minutes of $\mathrm{Ar}^{+}$and from 0.36 to 2.08 after 27 hours $\left(1.2 \times 10^{17}\right.$ photons $\left.\mathrm{cm}^{-2}\right)$ of X-ray irradiation (see Table 5$)$. The formation of cuprite $\left(\mathrm{Cu}_{2} \mathrm{O}\right)$ has also been observed after $\mathrm{KrF}$ laser irradiation of azurite tempera by FTRaman spectroscopy [7]. Although the appearance of $\mathrm{Cu}^{+}$in the first spectrum could have been induced at the first instants of $\mathrm{X}$-ray exposure, the slow, progressive increase of the $\mathrm{Cu}^{+}$ component, after both photon and ion irradiation, suggests a different process. In fact, the azurite pigment seems to have interacted chemically with the egg yolk binder during the curing process after sample preparation. The binder-inorganic pigment interaction has been identified for different pigments, being of relevance for malachite and azurite mixed with proteinaceous binders [40-44]. Different techniques have shown evidence of the interaction of azurite $\left(v i a \mathrm{Cu}^{2+}\right)$ with amino acids of several proteinaceous binders $[40,41]$ and with fatty acid esters of egg yolk [41]. Chemical changes in the copper-based pigment or the binder of the tempera have also been observed. Azurite pigment is known to enhance the oxidation of egg lipids in tempera media [44]. On the other side, under certain ambient conditions malachite decomposes and $\mathrm{Cu}_{2} \mathrm{O}$ forms more easily in the presence of egg yolk [42]. All these studies give plausible arguments for the previously suggested partial reduction of azurite pigment before the irradiation experiments are initiated.

$\mathrm{N} 1 \mathrm{~s}$ spectrum of azurite tempera is fitted with two components at $399.6 \mathrm{eV}$ (amine or amide) and $402.2 \mathrm{eV}$ (quaternary ammonium), the latter being related to phospholipids. At the end of the exposure to X-rays and ions, phospholipids and egg yolk proteins have been degraded as observed by their corresponding ratios on Table 5 . The $O 1 \mathrm{~s}$ spectrum can be fitted with three components at $530.9 \mathrm{eV}(\mathrm{N}-\mathrm{C}=\underline{\mathrm{O}}, \underline{\mathrm{O}}=\mathrm{C}-\mathrm{OH}, \underline{\mathrm{O}}=\mathrm{C}-\mathrm{OR}, \mathrm{P}=\underline{\mathrm{O}}, \mathrm{P}-\underline{\mathrm{O}}), 532.1 \mathrm{eV}(\mathrm{C}-\underline{\mathrm{O}}, \mathrm{C}-\underline{\mathrm{O}}-\mathrm{C})$ and $533.3 \mathrm{eV}(\mathrm{O}=\mathrm{C}-\underline{\mathrm{O}}, \mathrm{O}=\mathrm{C}-\underline{\mathrm{O}})$ for the ion treated azurite tempera. The peaks are shifted by 0.1 $\mathrm{eV}$ to lower binding energies for the tempera irradiated with $\mathrm{X}$-rays. The $\mathrm{O}_{530.9} / \mathrm{O}_{532.1}$ and $\mathrm{O}_{533.3} / \mathrm{O}_{532.1}$ ratios evolve similarly during both irradiation treatments (see Table 5). Finally, the C 1s spectrum is initially deconvoluted into four components at $284.6 \mathrm{eV}$ (C-C, C-H), at 286.0 $\mathrm{eV}(\mathrm{C}-\mathrm{O}, \mathrm{C}-\mathrm{N})$, at $287.4 \mathrm{eV}(\mathrm{C}=\mathrm{O}, \mathrm{O}-\mathrm{C}-\mathrm{O})$ and the component at $288.7 \mathrm{eV}(\mathrm{O}=\mathrm{C}-\mathrm{OH}, \mathrm{O}=\mathrm{C}-\mathrm{OR})$. The ratios of all the carbon components decreased with respect to $\mathrm{C}_{284.6}$ with similar tendencies for both kinds of irradiation, after overpassing a maximum value, which is reached after 8 hours of soft X-ray exposure and after 15 minutes of $\mathrm{Ar}^{+}$bombardment. $\mathrm{C}_{284.6}$ experiences the same small broadening of $0.2 \mathrm{eV}$ already observed for $\mathrm{C}_{284.6}$ in the alizarin tempera and probably associated with some hydrocarbon fragment deposition or changes in the polymeric network during azurite tempera irradiation. Besides these four components, an additional small fifth component at $283.0 \mathrm{eV}$ (carbide) is required to obtain a proper $\mathrm{C}$ 1s fitting as irradiation of azurite tempera continues. The $C_{283.0} / C_{284.6}$ ratio rises up to 0.02 after 60 minutes of ion irradiation, and until 0.04 after 27 hours of $\mathrm{X}$-ray exposure. As carbide was not detected in the pure azurite pigment, the interaction of the binder with azurite seems to lead to the formation of new carbon species after irradiation. Since the emergence of this component is delayed until a considerable copper pigment transformation is produced, the participation in the carbide formation of new copper species could be suspected. In fact, $\mathrm{Cu}$ based nanoparticles (metallic copper, copper oxides and some hybrid copper nanostructures) 
are used in catalysis for a wide range of organic transformations and for electrocatalysis and photocatalysis [45]. However, further investigations would be needed to clarify this point.

From the previous analysis we can state that cleavage of $\mathrm{C}-\mathrm{N}, \mathrm{C}-\mathrm{O}$ and/or $\mathrm{C}-\mathrm{OH}$ and of $\mathrm{C}=\mathrm{O}$ bonds in azurite tempera takes place at similar rates during both types of irradiation treatment, in addition to the increased copper chemical reduction of the pigment. As already mentioned, alizarin tempera experiences similar irradiation effects, except that the $\mathrm{C}=\mathrm{O}$ bond cleavage rate during $\mathrm{X}$-ray exposure is lower than that of the other modifications. The interaction of the copper-based pigment with proteins and lipids (possibly involving amides and carboxylic acids groups) could account for this different behaviour.

The physicochemical processes during irradiation with X-rays and ions, already mentioned for the pure copper pigments, are also taking place in the irradiated temperas. In this case, the Auger decay is expected to lead to cleavage of bonds between neighbouring atoms in organic materials [33] with the formation of some ionic species that can be subsequently desorbed. In addition, the Auger decay can induce chain scission in the organic compounds with the production of volatile fragments and the resulting mass loss in the irradiated area. The new generated species (ions and radicals) favour further transformations. The damage of the binder can induce further degradation of the copper pigment, and vice versa. In fact, the rate of reduction of $\mathrm{Cu}^{2+}$ to $\mathrm{Cu}^{+}$in the azurite tempera under the same irradiation conditions seems to be clearly enhanced in the presence of the binder in comparison with the pure azurite pigment (see Table 2 and 5). In spite of all these modifications shown by XPS, morphological or colour changes are not apparent in the acquired micro-photographs of the surface of the tempera paint before and after irradiation. On the other side, further investigations are necessary to understand the mechanisms leading to egg-yolk degradation. X-ray and ion degradation of the different components of egg yolk (such as phospholipids and triglycerides) would also deserve independent experimental efforts in order to give additional hints of the specific irradiation induced-damage mechanisms in this type of compounds. This group of experiments would help to distinguish between the irradiation damage of the binder alone and in the presence of a pigment.

Although to the best of our knowledge, XPS studies of X-ray or ion induced damage of temperas have not been published, $X$-ray induced damage of amino acids and DNA has attracted some attention due to the biological importance of these compounds [46-49]. The downward trend in $\mathrm{O} 1 \mathrm{~s}$ and $\mathrm{N} 1 \mathrm{~s}$ intensities with respect to the one of $\mathrm{C} 1 \mathrm{~s}$ in the present work has also been observed in X-ray irradiation of DNA [46,47] and amino acids through XPS analysis $[48,49]$. In the case of DNA, dehydrogenation, oxygen loss and radical formation was deduced from XPS data. The decrease of components related to $\mathrm{C}-\mathrm{OH}$ and $\mathrm{C}=\mathrm{O}$ groups in $\mathrm{C} 1 \mathrm{~s}$ and $O 1 \mathrm{~s}$, together with loss of amino groups were associated to base damage and strand breaks in the DNA samples. Studies of X-ray induced decomposition of five aliphatic amino acids [48] and two aromatic amino acids [49] by XPS were complemented by mass spectrometry and near-edge $\mathrm{X}$-ray absorption spectroscopy (NEXAFS). The detection of $\mathrm{H}_{2}$, $\mathrm{H}_{2} \mathrm{O}, \mathrm{CO}_{2}, \mathrm{CO}$ and $\mathrm{NH}_{2}$ upon X-ray exposure was dominant in the gas phase. From the combined analysis of these three techniques it was deduced that the amino acids are subjected to dehydrogenation (deprotonation), dehydration (water detachment by $\mathrm{C}-\mathrm{OH}$ bond scission), decarboxylation (detachment of $\mathrm{CO}_{2}$ ), decarbonylation (detachment of $\mathrm{CO}$ ) and 
deamination (detachment of ammonia due to $\mathrm{C}-\mathrm{N}$ bond scission). The observed dehydration at the surface was related to a strong loss of $\mathrm{O}$, decarboxylation and decarbonylation to a decrease of the second C component at $288.4 \mathrm{eV}$, and deamination to the decrease of the N/C ratio. The dominant decomposition route was shown to be dependent on the molecular structure of the specific amino acid. All these results reflect the variety of simultaneous chemical reactions and bond cleavage processes taking place. In the present work, the chemical complexity of the tempera samples complicates substantially the unambiguous identification of the chemical processes. In spite of this circumstance, and by comparison with the aforementioned studies, our XPS results suggest tentatively that dehydration, decarboxylation and deamination are taking place in both azurite and alizarin temperas.

\subsection{Irradiation damage threshold}

The acquisition conditions of XPS spectra indicated in section 2.1 and Table 1 can be considered as safe for the analysed samples since no degradation is detected. However, from the practical analysis of materials in cultural heritage it is also beneficial to define an X-ray damage threshold. This threshold allows the identification of a limit of dose (or time) where the damage starts to be clearly detected. Following common criteria in XPS $[20,50]$ the threshold is defined by the observation of a 10\% decrease in a selected XPS signal. This percentage is considered a reasonable indication of a damage threshold and is employed for the $\mathrm{X}$-rays and $\mathrm{Ar}^{+}$irradiation exposures shown in the previous sections. The procedure consists in the selection of a parameter characteristic of the sample $(Y)$ that is measured initially $\left(Y_{0}\right)$ and after certain time $\left(Y_{t}\right)$. When $Y_{t} / Y_{0}$ falls a $10 \%, t$ is the time that defines the damage threshold. This threshold can also be indicated as a dose. For azurite, malachite and azurite egg tempera the selected parameter is the ratio of areas of the $\mathrm{Cu}^{2+}$ component to the whole region of $\mathrm{Cu}\left(\mathrm{Y}=\mathrm{Cu}^{2+/} \mathrm{Cu} 2 \mathrm{p}\right)$. This ratio falls around a $10 \%$ after 15 hours of $\mathrm{X}$-ray irradiation of the azurite at $135 \mathrm{~W}$, which corresponds to a dose of $\sim 6.5 \times 10^{16}$ photons $\mathrm{cm}^{-2}$ at the Specs system. The time is extended to 19 hours $\left(\sim 8.2 \times 10^{16}\right.$ photons $\left.\mathrm{cm}^{-2}\right)$ for the irradiated malachite pigment by $\mathrm{X}$-rays in contrast to the malachite irradiated by $\mathrm{Ar}^{+}$, whose ratio falls a $13 \%$ in only 20 minutes. The damage threshold would be approximately 3 hours $\left(\sim 1.3 \times 10^{16}\right.$ photons $\mathrm{cm}^{-2}$ ) for azurite egg tempera under the selected X-ray conditions and roughly 5 minutes under $\mathrm{Ar}^{+}$irradiation. A suitable parameter $\mathrm{Y}$ that defines the damage threshold for alizarin egg tempera is the ratio $\mathrm{O} / \mathrm{C}$, which falls around a $10 \%$ after 11 hours and 30 minutes $\left(\sim 1.4 \times 10^{17}\right.$ photons $\left.\mathrm{cm}^{-2}\right)$ in the Leybold system. The selected parameters facilitate a quantitative estimation of the sensitivity of the different pictorials materials and define certain limits for the irradiation time intervals and doses that should not be reached in these experimental set-ups.

\section{Conclusions}

X-ray photoelectron spectroscopy has been successfully employed to characterize azurite, malachite and alizarin pigments, and their egg-yolk temperas, as well as to track the chemical effects of prolonged soft $\mathrm{X}$-ray exposure and consecutive Argon ion irradiation at relatively low energy conditions $(135 \mathrm{~W})$. It has been shown that an adequate selection of the measurement parameters (including power, number of scans and step energy) allows for the acquisition of different spectra of the pictorial samples with a reasonable signal-to-noise ratio and minimum 
induced irradiations effects as the ones indicated in section 2.1. On the other side, there is evidence that a chemical interaction between the azurite pigment and the egg yolk binder seems to take place, supporting previously published results. In contrast to the pure azurite pigment, the initial $\mathrm{Cu} 2 \mathrm{p}$ spectrum of azurite tempera displays a significant $\mathrm{Cu}^{+}$presence, together with the expected $\mathrm{Cu}^{2+}$ feature, indicating that the pigment is partially reduced before the actual irradiation damage experiment starts.

In relation to exposure to X-ray photons and $\mathrm{Ar}^{+}$ions, a distinct behaviour of the pictorial samples has been determined, depending on their composition. The present work has shown that both X-ray and ion irradiation induce the chemical reduction of the pure azurite and malachite pigments (a continuous increase of $\mathrm{Cu}^{+}$at the expense of $\mathrm{Cu}^{2+}$ signal intensity). As a result, $\mathrm{Cu}_{2} \mathrm{O}$ is formed, while hydroxyl-carbonate decomposition is also detected. On the contrary, the alizarin pigment does not experience any sort of chemical modification under $\mathrm{X}$ ray irradiation conditions equivalent to the ones applied on the copper-based pigments. Regarding the tempera paints, XPS determines a higher sensitivity than the pure pigments towards exposure to X-ray photons and ions. Despite the complexity of the analysed systems, the spectral component analysis allows to identify the preferential cleavage of $\mathrm{C}-\mathrm{N}, \mathrm{C}-\mathrm{O}$ and/or $\mathrm{C}-\mathrm{OH}$ and $\mathrm{C}=\mathrm{O}$ bonds. Under exposure to both types of irradiation, the molecular changes seem to imply decarboxylation, dehydration and deamination. In addition, the chemical reduction of copper in azurite tempera also progresses under both irradiation exposures.

The definition of a threshold damage (as a 10\% decrease in an XPS signal) is useful to establish limits of exposure to radiation that can minimize their impact. The ratio $\mathrm{Cu}^{2+/} \mathrm{Cu} 2 \mathrm{p}$ falls around a $10 \%$ after 15 hours $\left(\sim 6.5 \times 10^{16}\right.$ photons $\left.\mathrm{cm}^{-2}\right)$ of $X$-ray irradiation for the azurite pigment, after 19 hours $\left(\sim 8.2 \times 10^{16}\right.$ photons $\left.\mathrm{cm}^{-2}\right)$ for the irradiated malachite by X-rays and after 3 hours $\left(\sim 1.3 \times 10^{16}\right.$ photons $\left.\mathrm{cm}^{-2}\right)$ for azurite egg tempera. The threshold damage is reduced to few minutes for the irradiated samples by $\mathrm{Ar}^{+}$. The ratio $\mathrm{O} / \mathrm{C}$ falls around a $10 \%$ after 11 hours and 30 minutes $\left(\sim 1.4 \times 10^{17}\right.$ photons $\left.\mathrm{cm}^{-2}\right)$ for alizarin egg tempera. These values of time intervals (or doses) should not be reached under the experimental conditions selected in these experimental set-ups if degradation of the pictorial materials under study wants to be avoided.

Further studies with different techniques, in order to get supplementary insight in the induced damage in these materials at the molecular and atomic level, would be of great relevance. In addition to the aforementioned mass spectrometry (for analysis of gas phase species) and NEXAFS (for structural information with both atomic and functional group specificity) studies, we can mention the technique of electron paramagnetic resonance (EPR) spectroscopy for the identification of the created defects and radicals. Besides, in relation to the modified organic components, infrared spectroscopy could be useful especially in the new modalities of IR microspectroscopy and atomic force microscopy-infrared spectroscopy (AFM-IR).

In conclusion, due to its surface sensitivity, XPS can be employed to detect induced damage at the early stages of sample modification and before a change can be detected by optical microscopy, while it provides chemical information at the molecular level. Therefore, this technique can also be used as a complementary method to determine safety levels in the characterization of painting materials by other analytical techniques, traditionally employed in the field of cultural heritage. Since the technique requires sampling before it is transferred to 
the instrument, XPS can be particularly useful in the definition of mitigation strategies and protocols to avoid irradiation damage with model samples before a real artefact of similar composition wants to be analysed by synchrotron X-rays or ion beam techniques such as PIXE.

\section{Acknowledgments}

This work has been funded by EU project "Integrated Platform for the European Research Infrastructure on Cultural Heritage" (IPERION-CH, Ref. H2020-INFRAIA-2014-2015, GRANT n ${ }^{\circ}$ 654028), by Projects CTQ2016-75880-P and MAT2015-64110-CL-1-P from the Ministerio de Economía, Industria y Competitividad (MINECO, Spain), and by program GEOMATERIALES 2CM (Ref. CAM, S2013/MIT_2914) from the Community of Madrid. M. O. thanks CSIC for a contract and E. C. thanks technical support from J. de la Figuera and L. Martín-García at the Specs XPS chamber. Preparation of the tempera samples by F. Guerra-Librero (Artyco SL) is acknowledged.

\section{References}

[1] L. Bertrand, S. Schöeder, D. Anglos, M.B.H. Breese, K. Janssens, M. Moini, A. Simon, Mitigation strategies for radiation damage in the analysis of ancient materials, Trends Analyt. Chem. 66 (2015) 128-145.

[2] T. Calligaro, V. González, L. Pichon, PIXE analysis of historical paintings: is the gain worth the risk?, Nucl. Instrum. Methods Phys. Res. Sect. B 363 (2015) 135-143.

[3] C. Gervais, M. Thoury, S. Réguer, P. Gueriau, J. Mass, Radiation damages during synchrotron X-ray micro-analyses of Prussian blue and zinc white historic paintings: detection, mitigation and integration, Appl. Phys. A 121 (2015) 949-955.

[4] M. Oujja, P. Pouli, C. Domingo, C. Fotakis, M. Castillejo, Analytical spectroscopic investigation of wavelength and pulse duration effects on laser-induced changes of egg-yolkbased tempera paints, Appl. Spectrosc. 64 (2010) 528-536.

[5] E. Mattei, G. de Vivo, A. De Santis, C. Gaetani, C. Pelosi and U. Santamaria, Raman spectroscopic analysis of azurite blackening, J. Raman Spectrosc. 39 (2008) 302-306.

[6] A. De Santis, E. Mattei, Claudia Pelosi, Micro-Raman and stratigraphic studies of the paintings on the 'Cembalo' model musical instrument (A.D. 1650) and laser-induced degradation of the detected pigments, J. Raman Spectrosc. 38 (2007) 1368-1378.

[7] M. Castillejo, M. Martin, M. Oujja, D. Silva, R. Torres, A. Manousaki, V. Zafiropulos, O.F. van den Brink, R.M.A. Heeren, R. Teule, A. Silva, H. Gouveia, Analytical study of the chemical and physical changes induced by KrF laser cleaning of tempera paints, Anal. Chem. 74 (2002) 46624671.

[8] C. Gervais, M.A. Languille, G. Moretti, S. Réguer, X- ray photochemistry of Prussian blue cellulosic materials: evidence for a substrate-mediated redox process, Langmuir 31 (2015) 8168-8175.

[9] L. Beck, P.C. Gutiérrez, F. Miserque, L. Thomé, Proton beam modification of lead white pigments, Nucl. Instrum. Methods Phys. Res. Sect. B 307 (2013) 20-24.

[10] C. Altavilla, E. Ciliberto, Copper resinate: an XPS study of degradation, Appl. Phys. A 83 (2006) 699-703. 
[11] P. Pouli, D.C. Emmony, C.E. Madden, I. Sutherland, Studies towards a thorough understanding of the laser-induced discoloration mechanisms of medieval pigments, J. Cult. Heritage 4 (2003) 271s-275s.

[12] M. Oujja, M. Sanz, E. Rebollar, J.F. Marco, C. Domingo, P. Pouli, S. Kogou, C. Fotakis, M. Castillejo, Wavelength and pulse duration effects on laser induced changes on raw pigments used in paintings, Spectrochim. Acta A 102 (2013) 7-14.

[13] B.A. van Driel, T.A. Wezendonk, K.J. van den Berg, P.J. Kooymand, J. Gascond, J. Dik, Determination of early warning signs for photocatalytic degradation of titanium white oil paints by means of surface analysis, Spectrochim. Acta A 172 (2017) 100-108.

[14] C.d.A. Cennini, Il Libro dell'Arte, Dover Publications, New York, 1960.

[15] C.D. Wagner, L.E. Davis, M.V. Zeller, J.A. Taylor, R.H. Raymond, L.H. Gale, Empirical atomic sensitivity factors for quantitative analysis by electron spectroscopy for chemical analysis, Surf. Interface Anal. 3 (1981) 211-225.

[16] S. V. Pepper, D.R. Wheeler, Quantitative characterization of an x-ray source in an x-ray photoelectron spectroscopy system, Rev. Sci. Instrum. 71 (2000) 1509-1515.

[17] M.C. Biesinger, L.W.M. Lau, A.R. Gerson, R.St.C. Smart, Resolving surface chemical states in XPS analysis of first row transition metals, oxides and hydroxides: Sc, Ti, V, Cu and Zn, Appl. Surf. Sci. 257 (2010) 887-898.

[18] N.S. McIntyre, M.G. Cook, X-Ray Photoelectron Studies on Some Oxides and Hydroxides of Cobalt, Nickel, and Copper, Anal. Chem. 47 (1975) 2208-2213.

[19] D.A. Svintsitskiy, T.Y. Kardash, O.A. Stonkus, E.A. Slavinskaya, A.I. Stadnichenko, V. Sergei, S.V. Koscheev, A.P. Chupakhin, A.I. Boronin, In situ XRD, XPS, TEM, and TPR study of highly active in CO oxidation CuO nanopowders, J. Phys. Chem. C 117 (2013) 14588-14599.

[20] G. Beamson, D. Briggs, High resolution XPS of organic polymers: The Scienta ESCA300 database, John Wiley \& Sons, Chichester, 1992.

[21] E. Cano, M.F. López, J. Simancas, J.M. Bastidas, X-ray photoelectron spectroscopy study on the chemical composition of copper tarnish products formed at low humidities, J. Electrochem. Soc. 148 (2001) E26-E30.

[22] Y. lijima, N. Niimura, K. Hiraoka, Prevention of the reduction of CuO during X-ray photoelectron spectroscopy analysis, Surf. Interface Anal. 24 (1996) 193-197.

[23] C.C. Chusuei, M.A. Brookshier, D.W. Goodman, Correlation of relative X-ray photoelectron spectroscopy shake-up intensity with CuO particle size, Langmuir 15 (1999) 2806-2808.

[24] S.P. Chenakin, R. Szukiewicz, R. Barbosa, N. Kruse, Surface analysis of transition metal oxalates: damage aspects, J. Electron Spectrosc. Relat. Phenom. 209 (2016) 66-77.

[25] D.C. Frost, A. Ishitani and C.A. McDowell, X-ray photoelectron spectroscopy of copper compounds, Mol. Phys. 24 (1972) 861-877.

[26] T.H. Fleisch, G.W. Zajac, J.O. Schreiner, G.J. Mains, An XPS study of the UV photoreduction of transition and noble metal oxides, Appl. Surf. Sci. 26 (1986) 448-497.

[27] M. Chappé, J. Hildenhagen, K. Dickmann, M. Bredol, Laser irradiation of medieval pigments at IR, VIS and UV wavelengths, J. Cult. Heritage 4 (2003) 264s-270s.

[28] S. Dedera, M. Burchard, U.A. Glasmacher, N. Schöppner, C. Trautmann D. Severin, A. Romanenko, C. Hubert, On-line Raman spectroscopy of calcite and malachite during irradiation with swift heavy ions, Nucl. Instrum. Methods Phys. Res., Sect. B 365 (2015) 564-568.

[29] G. Panzner, B. Egert, H.P. Schmidt, The stability of $\mathrm{CuO}$ and $\mathrm{Cu}_{2} \mathrm{O}$ surfaces during argon sputtering studied by XPS and AES, Surf. Sci. 151 (1985) 400-408. 
[30] G. Marletta, Cation dependence of the chemical modifications induced by low energy particle bombardment on inorganic salts: an XPS study, Nucl. Instr. Meth. B 32 (1988) 204-210.

[31] R.L. Frost, Z. Ding, J.T. Kloprogge, W.N. Martens, Thermal stability of azurite and malachite in relation to the formation of mediaeval glass and glazes, Thermochim. Acta 390 (2002) 133144.

[32] H. Lüth, Surfaces and interfaces of solid materials, Springer-Verlag, Berlin Heildelberg, 1995.

[33] V. E. Henrich, P.A. Cox, The surface science of metal oxides, Cambridge University Press, Cambridge, 1994.

[34] J. Cazaux, A physical approach to the radiation damage mechanisms induced by X-rays in X-ray microscopy and related techniques, J. Microsc. 188 (1997) 106-124.

[35] M. Anton, Composition and structure of Hen egg yolk, in: R. Huopalahti, R. López-Fandiño, M. Anton, R. Schade (Eds.), in Bioactive egg compounds Springer-Verlag: Berlin Heidelberg, 2007, pp 1-6.

[36] P.G. Rouxhet, A.M. Misselyn-Bauduin, F. Ahimou, M.J. Genet, Y. Adriaensen, T. Desille, P. Bodson, C. Deroanne, XPS analysis of food products: toward chemical functions and molecular compounds, Surf. Interface Anal. 40 (2008) 718-724.

[37] R.H. West, M. Odlyha, K. Pratt, A. Roberts, S. Hutton, Monitoring the environmental degradation of paint dosimeters used to assess risk for fine art paintings on display by XPS, Surf. Interface Anal. 36 (2004) 862-865.

[38] C.J.P. Boonaert, P.G. Rouxhet, Surface of lactic acid bacteria: relationships between chemical composition and physicochemical properties, Appl. Environ. Microbiol. 66 (2000) 2548-2554.

[39] O.F. van den Brink, Molecular changes in egg tempera paint dosimeters as tools to monitor the museum environment, University of Amsterdam, 2001.

[40] C. Duce, E. Bramanti, L. Ghezzi, L. Bernazzani, I. Bonaduce, M.P. Colombini, A. Spepi, S. Biagi, M.A. Tine, Interactions between inorganic pigments and proteinaceous binders in reference paint reconstructions, Dalton Trans. 42 (2013) 5975-5984.

[41] J. Romero-Pastor, C. Cardell, E. Manzano, A. Yebra-Rodríguez, N. Navas, Assessment of Raman microscopy coupled with principal component analysis to examine egg yolk-pigment interaction based on the protein $\mathrm{C}-\mathrm{H}$ stretching region $\left(3100-2800 \mathrm{~cm}^{-1}\right)$, J. Raman Spectrosc. 42 (2011) 2137-2142.

[42] T. Špec, K. Retko, P. Ropret, A. Meden, J. Bernard, The influence of UV-Vis radiation, and oscillations of temperature and relative humidity, on malachite alteration in the presence of different organic binders and varnishes, J. Raman Spectrosc. 45 (2014) 1068-1075.

[43] M. Odlyha, N.S. Cohen, G.M. Foster, R.H. West, Dosimetry of paintings: determination of the degree of chemical change in museum exposed test paintings (azurite tempera) by thermal and spectroscopic analysis, Thermochim. Acta 365 (2000) 53-63.

[44] O.F. van den Brink, J.J. Boon, P.B. O'Connor, M.C. Duursma, R.M.A. Heeren, Matrixassisted laser desorption/ionization Fourier transform mass spectrometric analysis of oxygenated triglycerides and phosphatidylcholines in egg tempera paint dosimeters used for environmental monitoring of museum display conditions, J. Mass Spectrom. 36 (2001) 479492. 
[45] M.B. Gawande, A. Goswami, F.-X. Felpin, T. Asefa, X. Huang, R. Silva, X. Zou, R. Zboril, R.S. Varma, $\mathrm{Cu}$ and $\mathrm{Cu}$-based nanoparticles: synthesis and applications in catalysis, Chem. Rev. 116 (2006) 3722-3811.

[46] S. Ptasińska, A. Stypczyńska, T. Nixon, N.J. Mason, D.V. Klyachko, L. Sanche, X-ray induced damage in DNA monitored by X-ray photoelectron spectroscopy, J. Chem. Phys. 129 (2008) 065102

[47] A. Stypczyńska, T. Nixon, N. Mason, X-ray radiation of poly-L-arginine hydrochloride and multilayered DNA-coatings, Eur. Phys. J. D 68 (2014) 333.

[48] Y. Zubavichus, O. Fuchs, L. Weinhardt, C. Heske, E. Umbach, J.D. Denlinger, M. Grunze, Soft X-ray-induced decomposition of Amino Acids: An XPS, mass spectrometry, and NEXAFS study, Radiat. Res. 161 (2004) 346-358.

[49] Y. Zubavichus, M. Zharnikov, A. Shaporenko, O. Fuchs, L. Weinhardt, C. Heske, E. Umbach, J.D. Denlinger, M. Grunze, Soft X-ray induced decomposition of phenylalanine and tyrosine: A comparative study, J. Phys. Chem. A 108 (2004) 4557-4565.

[50] D.R. Baer, M.H. Engelhard, A.S. Lea, D.J. Gaspar, Comparing beam damage rates using susceptibility tables, in: D. Briggs, J. T. Grant (Eds.), in Surface Analysis by Auger and X-ray Photoelectron Spectroscopy, IM Publications and SurfaceSpectra Limited, Chichester Manchester, 2003, pp 843-856. 


\section{Figure captions}

Fig. 1. Evolution of $\mathrm{Cu} 2 \mathrm{p}$ XPS spectra of the azurite pigment at the indicated time intervals during a prolonged soft $\mathrm{X}$-ray $(\mathrm{Mg} \mathrm{K \alpha})$ exposure at $135 \mathrm{~W}$. Curve fitting of $\mathrm{Cu} 2 \mathrm{p}_{3 / 2}$ displays the increase of $\mathrm{Cu}^{+}$oxidation state with respect to $\mathrm{Cu}^{2+}$ after $\mathrm{X}$-ray irradiation.

Fig. 2. $\mathrm{C} 1 \mathrm{~s}$ and $\mathrm{O} 1 \mathrm{~s}$ XPS spectra of the azurite pigment at the indicated irradiation times during the same prolonged $X$-ray exposure of Fig. 1.

Fig. 3. $\mathrm{Cu} 2 \mathrm{p}, \mathrm{O} 1 \mathrm{~s}$ and $\mathrm{C} 1 \mathrm{~s}$ XPS spectra of malachite at the indicated irradiation times during a continuous X-ray exposure (a) and after consecutive $\mathrm{Ar}^{+}$irradiation intervals (b). Exposure to both $\mathrm{X}$-ray photons and ions induces a comparable degradation of malachite. See text for further details.

Fig. 4. Evolution of $\mathrm{C} 1 \mathrm{~s}$ and $\mathrm{O} 1 \mathrm{~s}$ photoelectron spectra of the alizarin pigment at the indicated irradiation times during $\mathrm{X}$-ray $(\mathrm{Mg} \mathrm{K} \alpha)$ exposure up to around 25 hours at $135 \mathrm{~W}$. For this pigment, the irradiation damage at the selected experimental conditions is undetectable.

Fig. 5. Evolution of $\mathrm{N} 1 \mathrm{~s}, \mathrm{C} 1 \mathrm{~s}$ and $\mathrm{O} 1 \mathrm{~s}$ XPS spectra of alizarin tempera at the indicated irradiation times during $\mathrm{X}$-ray $(\mathrm{Mg} \mathrm{K} \alpha)$ exposure at $135 \mathrm{~W}$.

Fig. 6. Cu 2p, N 1s, $\mathrm{O} 1 \mathrm{~s}$ and $\mathrm{C} 1 \mathrm{~s}$ photoelectron spectra of azurite tempera during prolonged $\mathrm{X}$ ray exposure (a) and after consecutive $\mathrm{Ar}^{+}$irradiation intervals (b). The surface irradiationinduced effects are similar for exposure to both $\mathrm{X}$-ray photons and $\mathrm{Ar}^{+}$. See text for further details. 
Table 1. Total acquisition time (in minutes) for each selected core level XPS spectrum

\begin{tabular}{l|cccc}
\hline Irradiated samples & Cu 2p & C 1s & O 1s & N 1s \\
\hline Azurite & 25 & 10 & 6 & - \\
Malachite & 25 & 10 & 6 & - \\
Alizarin & - & 19 & 8 & - \\
Alizarin tempera & - & 10 & 15 & 45 \\
Azurite tempera (X-rays) & $70^{\mathrm{a}}$ & 7 & 11 & 30 \\
Azurite tempera (Ar ${ }^{+}$) & 70 & 7 & 14 & 32 \\
\hline
\end{tabular}

a 12 minutes for the first spectrum of the series. 
Table 2. Ratios of areas of components in the XPS spectra of azurite acquired during prolonged $\mathrm{X}$-ray exposure.

\begin{tabular}{l|cccccc}
\hline XPS peak area ratios & \multicolumn{7}{|c}{ X-ray irradiation (hours) } \\
& 1 & 10 & 20 & 35 & 44 & 55 \\
\hline $\mathrm{Cu}^{+} / \mathrm{Cu}^{2+}$ & 0,03 & 0,10 & 0,18 & 0,26 & 0,34 & 0,43 \\
$\mathrm{O}_{529.9} /\left(\mathrm{O}_{531.4}+\mathrm{O}_{532.9}\right)$ & 0,06 & 0,07 & 0,07 & 0,08 & 0,09 & 0,10 \\
\hline $\mathrm{O}_{529.9} /\left(\mathrm{O}_{529.9}\right)^{0}$ & 1,00 & 1,00 & 1,01 & 1,04 & 1,20 & 1,22 \\
$\mathrm{O}_{531.4} /\left(\mathrm{O}_{531.4}\right)^{0}$ & 1,00 & 0,95 & 0,91 & 0,86 & 0,83 & 0,80 \\
$\mathrm{O}_{532.9} /\left(\mathrm{O}_{532.9}\right)^{0}$ & 1,00 & 0,98 & 0,94 & 0,79 & 0,75 & 0,62 \\
$\mathrm{C}_{289.1} /\left(\mathrm{C}_{289.1}\right)^{0}$ & 1,00 & 0,92 & 0,90 & 0,88 & 0,83 & 0,83 \\
\hline
\end{tabular}

${ }^{a}$ The estimation of the $\mathrm{Cu}^{2+}$ area includes the area of the component at $934.6 \mathrm{eV}$ and the areas of the shake-up satellites.

${ }^{\mathrm{b}}$ The "0" superscript refers to the first spectra at the beginning of irradiation by X-rays. 
Table 3. Ratios of areas of components in the XPS spectra of malachite acquired during prolonged X-ray exposure and after successive $\mathrm{Ar}^{+}$irradiations. Same notation as in Table 2.

\begin{tabular}{|c|c|c|c|c|c|c|c|c|c|c|c|c|}
\hline \multirow[t]{2}{*}{ XPS peak area ratios } & \multicolumn{6}{|c|}{ X-ray irradiation (hours) } & \multicolumn{6}{|c|}{$\mathrm{Ar}^{+}$irradiation (minutes) } \\
\hline & 1 & 9 & 19 & 35 & 45 & 59 & 0 & 10 & 20 & 25 & 40 & 60 \\
\hline $\mathrm{Cu}^{+} / \mathrm{Cu}^{2+}$ & 0,00 & 0,08 & 0,19 & 0,26 & 0,30 & 0,41 & 0,11 & 0,16 & 0,28 & 0,37 & 0,46 & 0,63 \\
\hline $\mathrm{O}_{529.9} /\left(\mathrm{O}_{531.4}+\mathrm{O}_{532.9}\right)$ & 0,03 & 0,05 & 0,06 & 0,06 & 0,07 & 0,08 & 0,03 & 0,05 & 0,08 & 0,09 & 0,13 & 0,13 \\
\hline $\mathrm{O}_{529.9} /\left(\mathrm{O}_{529.9}\right)^{0}$ & 1,00 & 1,54 & 1,62 & 1,64 & 1,84 & 2,04 & 1,00 & 1,91 & 2,93 & 3,34 & 4,11 & 4,08 \\
\hline $\mathrm{O}_{531.4} /\left(\mathrm{O}_{531.4}\right)^{0}$ & 1,00 & 0,97 & 0,90 & 0,89 & 0,85 & 0,82 & 1,00 & 0,98 & 0,95 & 0,92 & 0,83 & 0,83 \\
\hline $\mathrm{O}_{532.9} /\left(\mathrm{O}_{532.9}\right)^{0}$ & 1,00 & 0,96 & 0,77 & 0,71 & 0,65 & 0,54 & 1,00 & 0,98 & 0,96 & 0,86 & 0,84 & 0,76 \\
\hline$C_{289.1} /\left(C_{289.1}\right)^{0}$ & 1,00 & 1,00 & 0,97 & 0,96 & 0,93 & 0,87 & 1,00 & 1,02 & 1,03 & 0,97 & 0,92 & 0,90 \\
\hline
\end{tabular}


Table 4. Ratios of areas of the various components in the XPS spectra of alizarin tempera acquired during prolonged $\mathrm{X}$-ray exposure.

\begin{tabular}{l|ccccc}
\hline $\begin{array}{c}\text { XPS peak area } \\
\text { ratios }\end{array}$ & 2 & 9 & 17 & 22 & 27 \\
\hline $\mathrm{N} \mathrm{1s} / \mathrm{C} 1 \mathrm{~s}$ & 0,024 & 0,023 & 0,021 & 0,019 & 0,018 \\
$\mathrm{O} 1 \mathrm{~s} / \mathrm{C} 1 \mathrm{~s}$ & 0,148 & 0,141 & 0,115 & 0,102 & 0,092 \\
\hline $\mathrm{O}_{530.9} / \mathrm{O}_{531.9}$ & 0,34 & 0,44 & 0,54 & 0,58 & 0,63 \\
$\mathrm{O}_{533.2} / \mathrm{O}_{531.9}$ & 0,42 & 0,37 & 0,42 & 0,40 & 0,42 \\
$\mathrm{C}_{286.0} / \mathrm{C}_{284.6}$ & 0,12 & 0,10 & 0,10 & 0,10 & 0,10 \\
$\mathrm{C}_{287.5} / \mathrm{C}_{284.6}$ & 0,06 & 0,05 & 0,04 & 0,04 & 0,03 \\
$\mathrm{C}_{288.5} / \mathrm{C}_{284.6}$ & 0,04 & 0,02 & 0,02 & 0,02 & 0,02 \\
$\mathrm{~N}_{399.6} /\left(\mathrm{N}_{399.6}\right)^{0}$ & 1,00 & 0,97 & 0,75 & 0,78 & 0,55 \\
$\mathrm{~N}_{402.2} /\left(\mathrm{N}_{402.2}\right)^{0}$ & 1,00 & 0,90 & 0,81 & 0,71 & 0,71 \\
\hline
\end{tabular}

a The "0" superscript refers to the first spectra at the beginning of the X-ray irradiation. 
Table 5. Ratios of areas of the various components in the XPS spectra of azurite tempera acquired during a prolonged $\mathrm{X}$-ray exposure and after successive $\mathrm{Ar}^{+}$irradiations.

\begin{tabular}{l|cccc|cccc}
\hline \begin{tabular}{c} 
XPS peak area \\
\multicolumn{1}{c|}{ ratios }
\end{tabular} & 3 & 8 & 18 & 27 & \multicolumn{4}{c}{$\mathrm{Ar}^{+}$irradiation (minutes) } \\
\hline $\mathrm{N} \mathrm{1s} / \mathrm{C} 1 \mathrm{~s}$ & 0,028 & 0,035 & 0,032 & 0,030 & 0,031 & 0,040 & 0,036 & 0,030 \\
$\mathrm{O} 1 \mathrm{~s} / \mathrm{C} 1 \mathrm{~s}$ & 0,205 & 0,234 & 0,211 & 0,188 & 0,209 & 0,253 & 0,232 & 0,203 \\
\hline $\mathrm{Cu}^{+} / \mathrm{Cu}^{2+}$ & 0,36 & 0,59 & 1,22 & 2,08 & 0,38 & 0,82 & 1,07 & 1,35 \\
$\mathrm{O}_{530.9} / \mathrm{O}_{531.9}$ & 0,35 & 0,43 & 0,45 & 0,46 & 0,40 & 0,39 & 0,41 & 0,37 \\
$\mathrm{O}_{533.2} / \mathrm{O}_{531.9}$ & 0,39 & 0,40 & 0,41 & 0,46 & 0,39 & 0,38 & 0,42 & 0,44 \\
$\mathrm{C}_{283.0} / \mathrm{C}_{284.6}$ & 0,01 & 0,03 & 0,04 & 0,04 & 0,01 & 0,01 & 0,02 & 0,02 \\
$\mathrm{C}_{286.0} / \mathrm{C}_{284.6}$ & 0,27 & 0,26 & 0,23 & 0,20 & 0,28 & 0,32 & 0,27 & 0,25 \\
$\mathrm{C}_{287.5} / \mathrm{C}_{284.6}$ & 0,05 & 0,07 & 0,07 & 0,06 & 0,05 & 0,08 & 0,07 & 0,07 \\
$\mathrm{C}_{288.5} / \mathrm{C}_{284.6}$ & 0,07 & 0,07 & 0,05 & 0,04 & 0,07 & 0,08 & 0,07 & 0,06 \\
$\mathrm{C}_{284.6} /\left(\mathrm{C}_{284.6}\right)^{0}$ & 1,00 & 0,95 & 0,97 & 1,01 & 1,00 & 0,89 & 0,93 & 0,97 \\
$\mathrm{~N}_{399.6} /\left(\mathrm{N}_{399.6}\right)^{0}$ & 1,00 & 1,00 & 0,93 & 0,77 & 1,00 & 1,06 & 0,93 & 0,81 \\
$\mathrm{~N}_{402.2} /\left(\mathrm{N}_{402.2}\right)^{0}$ & 1,00 & 1,25 & 1,19 & 1,10 & 1,00 & 1,29 & 1,17 & 1,00 \\
$\mathrm{~N}_{399.6} / \mathrm{N}_{402.2}$ & 0,36 & 0,29 & 0,25 & 0,25 & 0,34 & 0,28 & 0,27 & 0,28 \\
\hline
\end{tabular}

${ }^{a} \mathrm{Cu}^{2+}$ area estimation includes the area of the component at $934.6 \mathrm{eV}$ and the areas of the shake-up satellites.

${ }^{\mathrm{b}}$ The "0" superscript refers to the first spectra at the beginning of the X-ray irradiation. 
Fig. 1 Evolution of $\mathrm{Cu} 2 p$ XPS spectra of the azurite pigment at the indicated time intervals during a prolonged soft X-ray $\left(\mathrm{Mg} \mathrm{K}_{\alpha}\right)$ exposure at $135 \mathrm{~W}$. Curve fitting of $\mathrm{Cu} 2 \mathrm{p}_{3 / 2}$ displays the

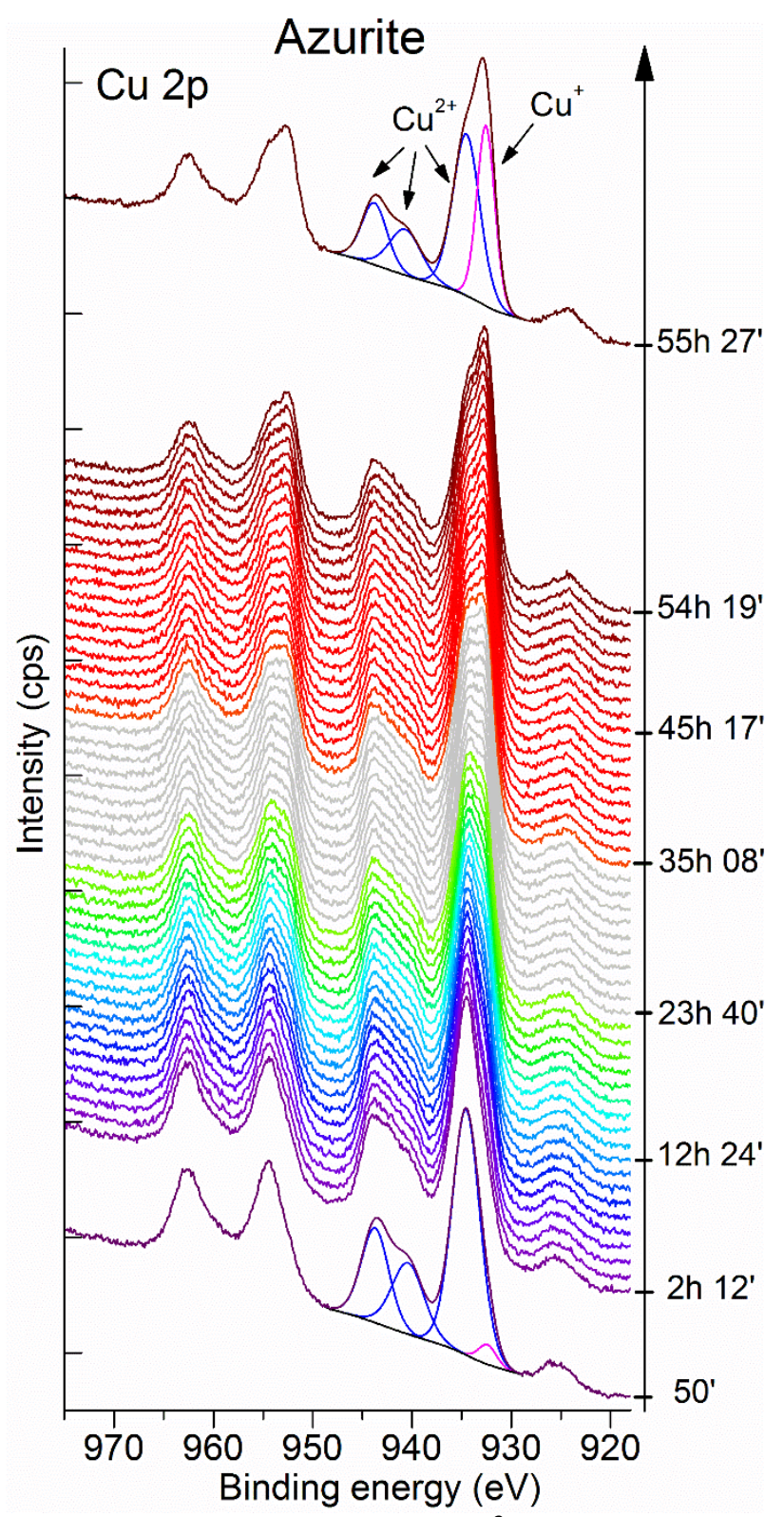

increase of $\mathrm{Cu}^{+}$oxidation state with respect to $\mathrm{Cu}^{2+}$ after $\mathrm{X}$-ray irradiation. 
Fig. $2 \mathrm{C} 1 \mathrm{~s}$ and $\mathrm{O}$ 1s XPS spectra of the azurite pigment at the indicated irradiation times during the same prolonged $\mathrm{X}$-ray exposure of Figure 1.
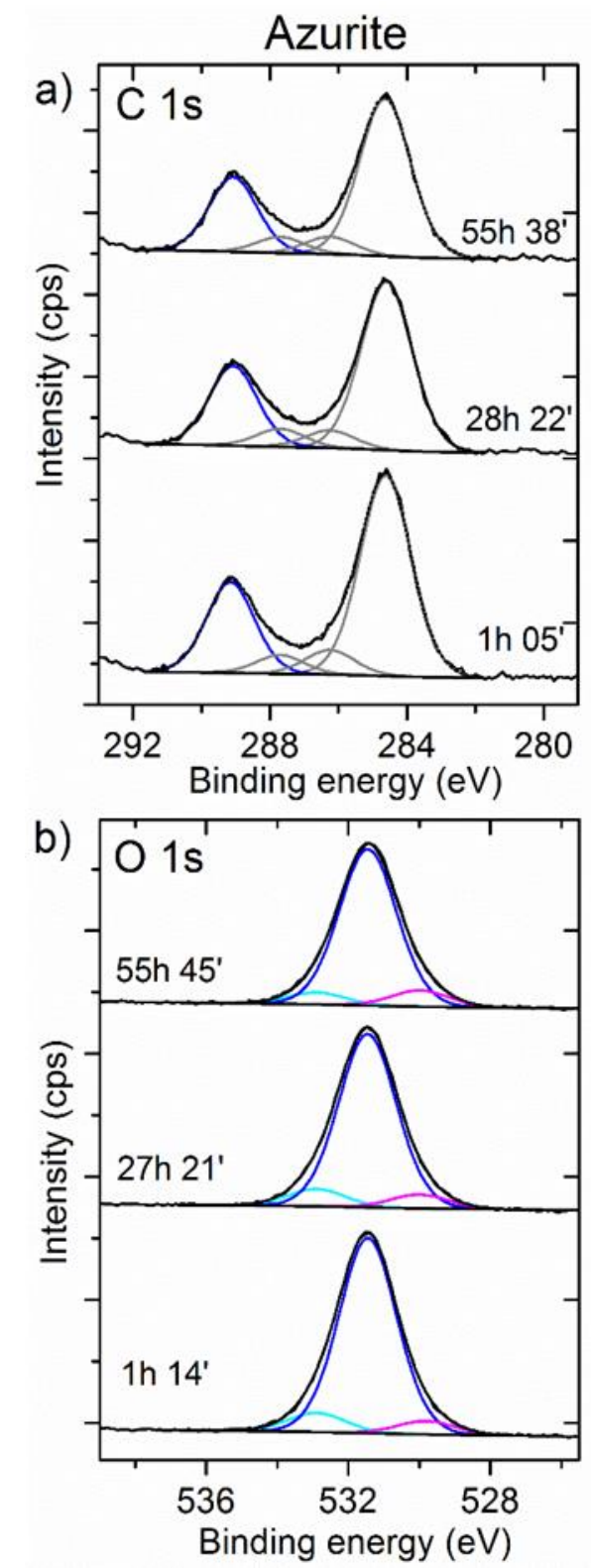
Fig. $2 \mathrm{Cu} 2 \mathrm{p}, \mathrm{O} 1 \mathrm{~s}$ and $\mathrm{C}$ 1s XPS spectra of malachite at the indicated irradiation times during a continuous X-ray exposure (a) and after consecutive $\mathrm{Ar}^{+}$irradiation intervals (b). Exposure to both $\mathrm{X}$-ray photons and ions induces a comparable degradation of malachite. See text for further details.

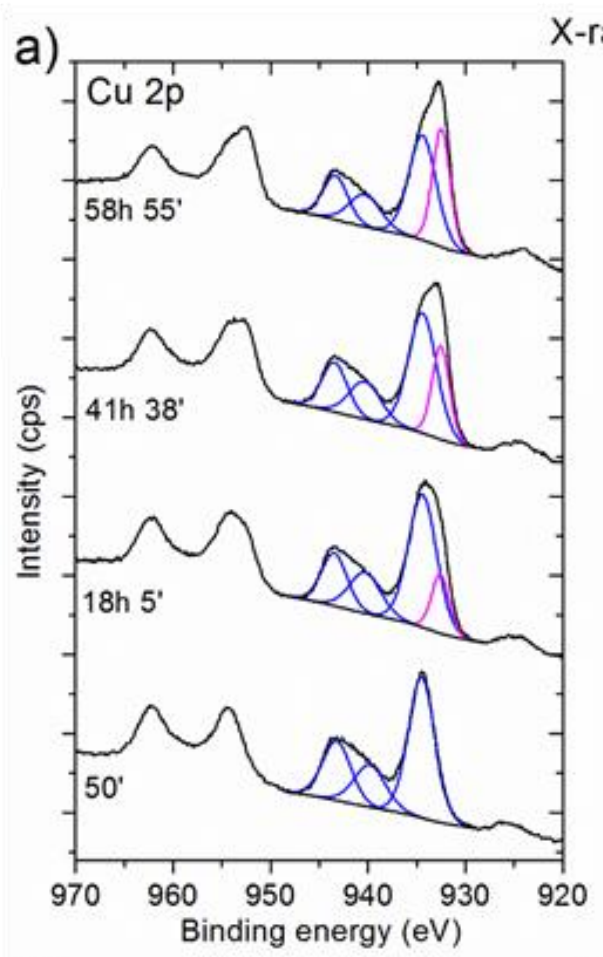

X-ray Irradiation of Malachite

b)
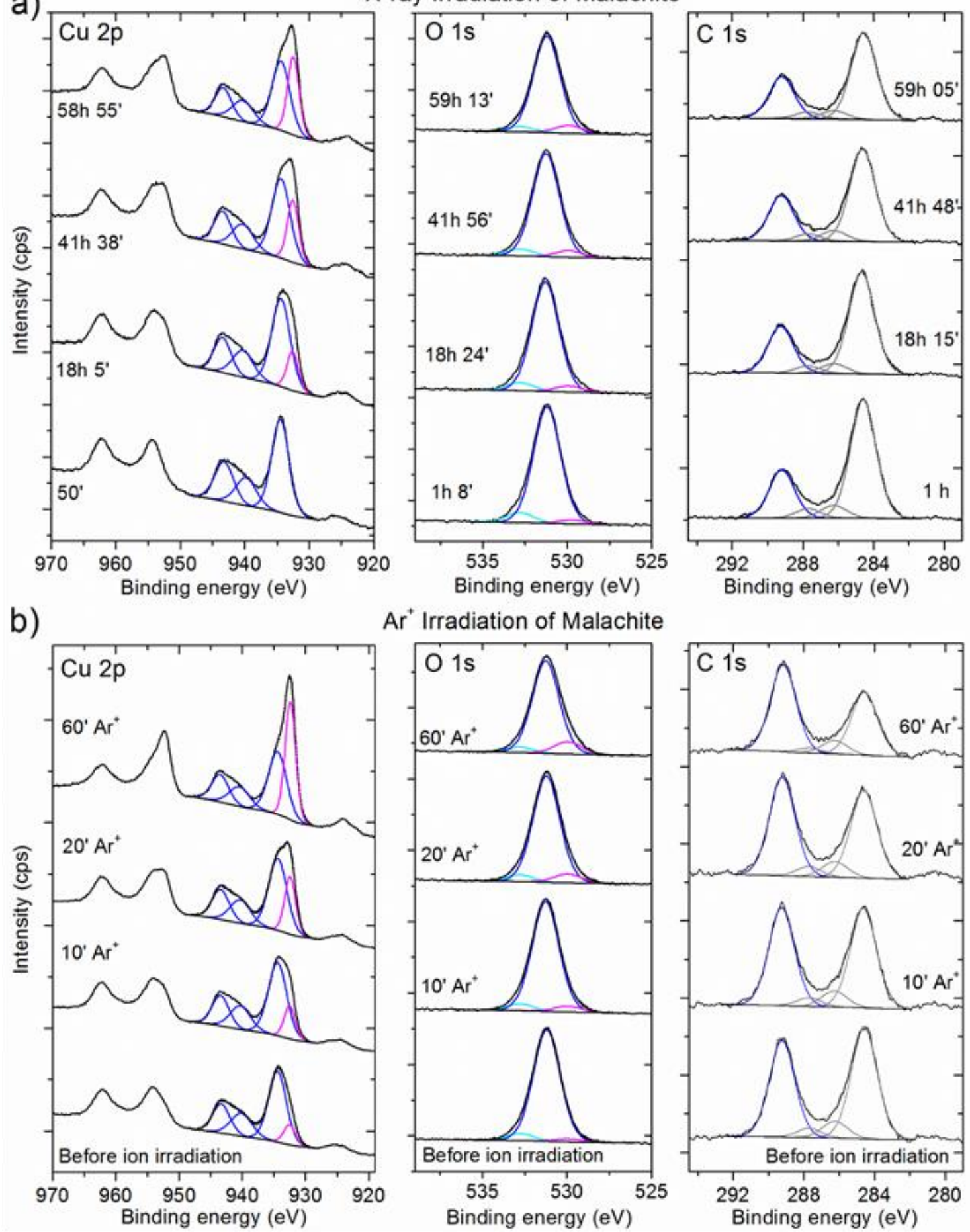

$\mathrm{Ar}^{+}$Irradiation of Malachite
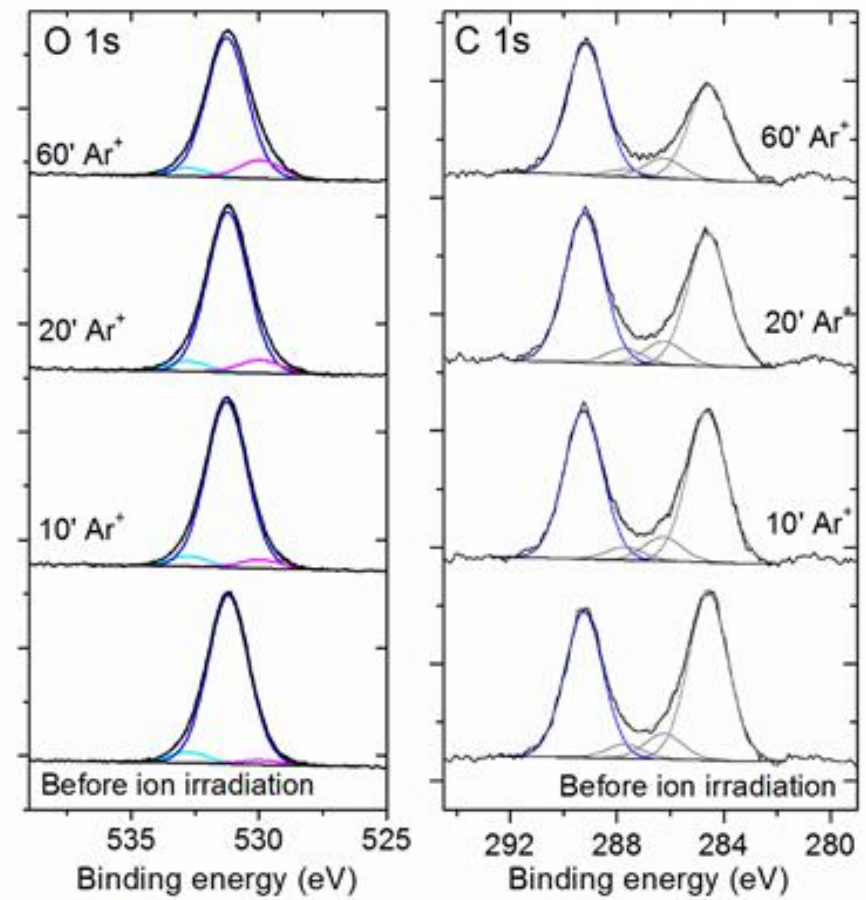
Fig. 3 Evolution of $\mathrm{C} 1 \mathrm{~s}$ and $\mathrm{O} 1 \mathrm{~s}$ photoelectron spectra of the alizarin pigment at the indicated irradiation times during $\mathrm{X}$-ray $\left(\mathrm{Mg} \mathrm{K}_{\alpha}\right)$ exposure up to around 25 hours at $135 \mathrm{~W}$. For this pigment, the irradiation damage at the selected experimental conditions is undetectable.
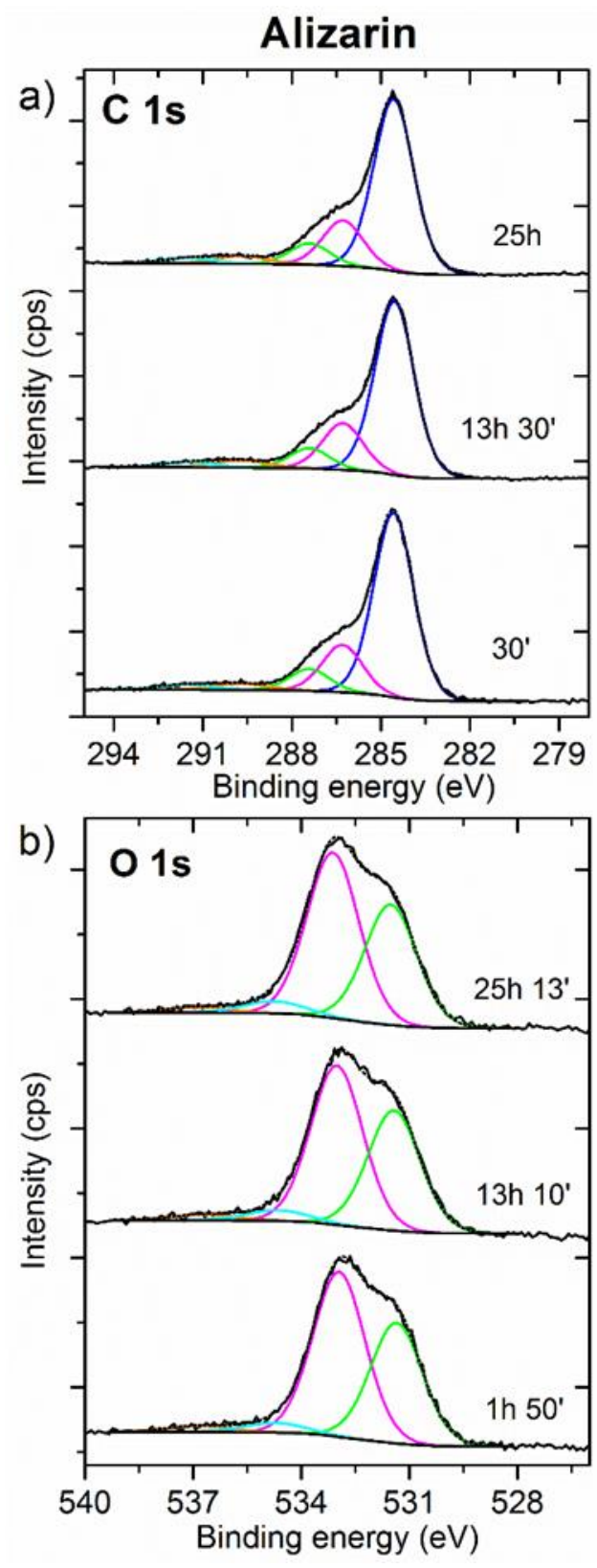
Fig. 4 Evolution of $\mathrm{N} 1 \mathrm{~s}, \mathrm{C} 1 \mathrm{~s}$ and $\mathrm{O}$ 1s XPS spectra of alizarin tempera at the indicated irradiation times during $\mathrm{X}$-ray $\left(\mathrm{Mg} \mathrm{K}_{\alpha}\right)$ exposure at $135 \mathrm{~W}$.

X-ray Irradiation of Alizarin Tempera
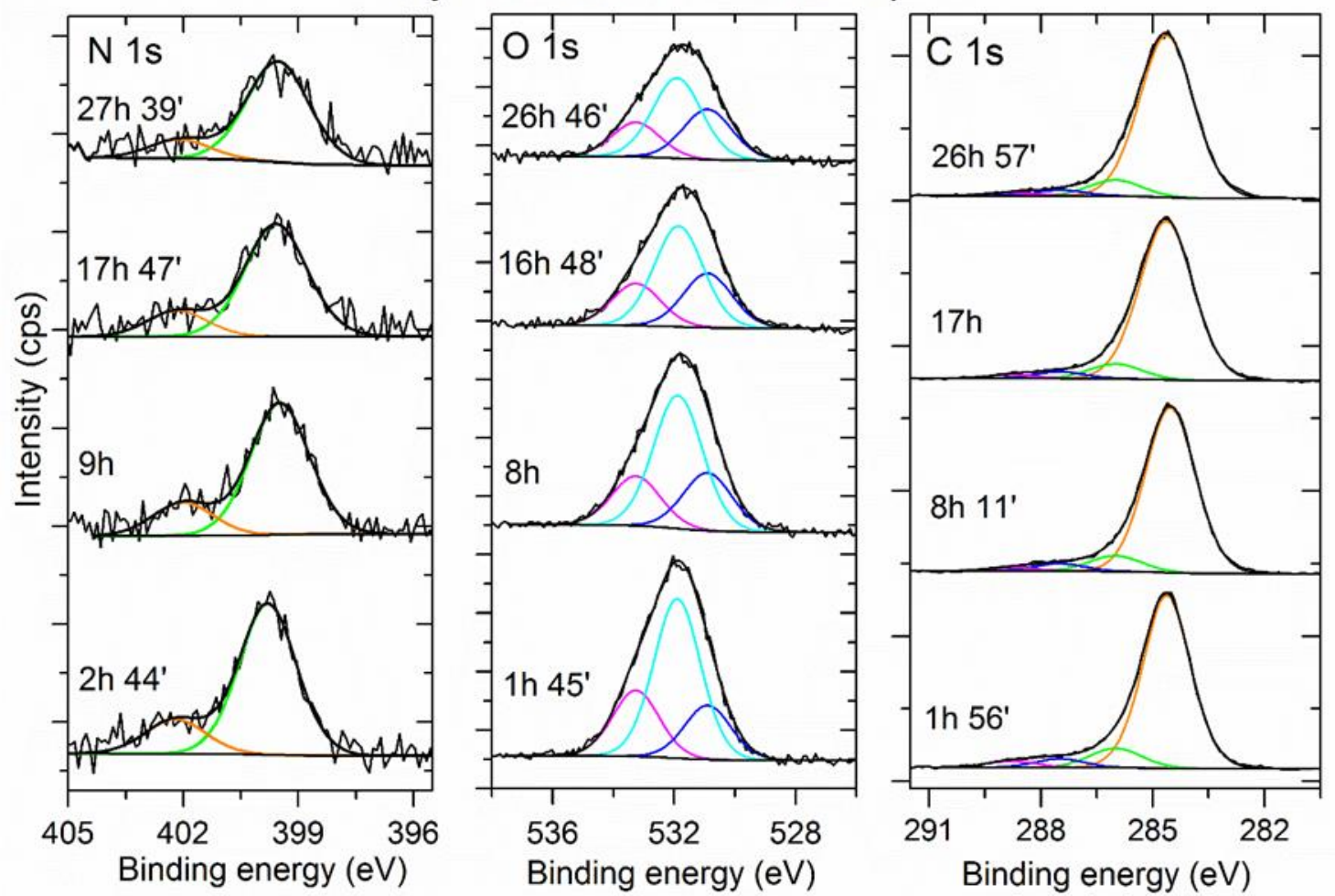
Fig. $5 \mathrm{Cu} 2 \mathrm{p}, \mathrm{N} 1 \mathrm{~s}, \mathrm{O} 1 \mathrm{~s}$ and $\mathrm{C}$ 1s photoelectron spectra of azurite tempera during prolonged $\mathrm{X}$ ray exposure (a) and after consecutive $\mathrm{Ar}^{+}$irradiation intervals (b). The surface irradiationinduced effects are similar for exposure to both X-ray photons and $\mathrm{Ar}^{+}$. See text for further details.

a)

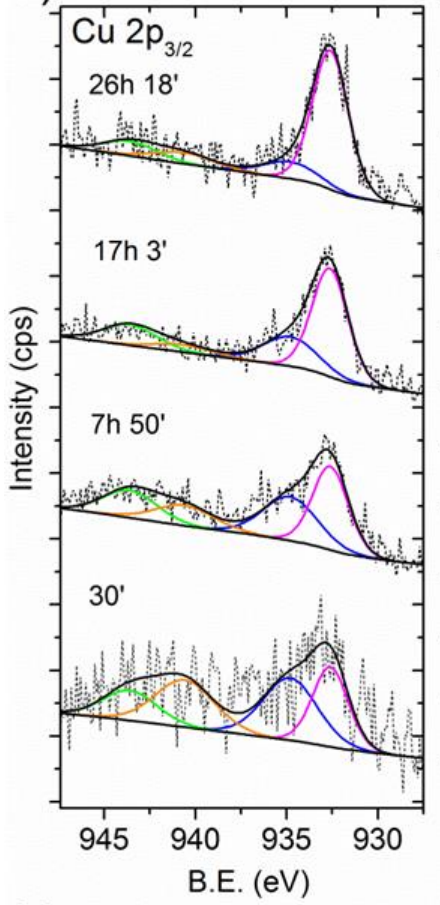

b)

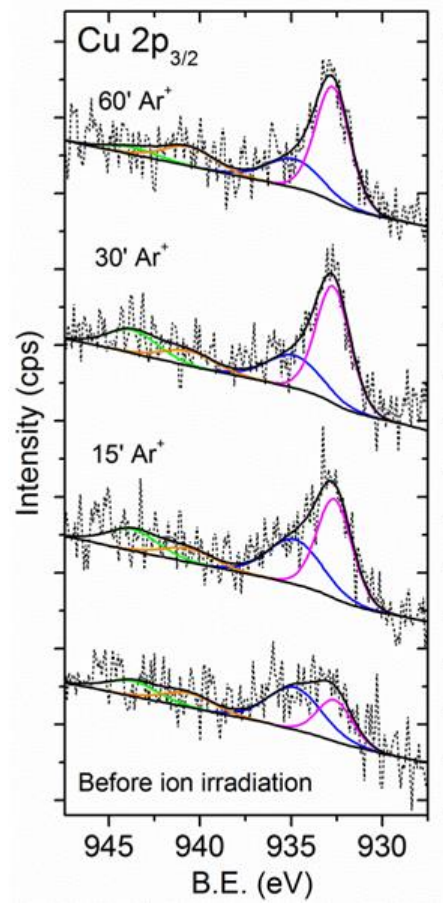

X-ray Irradiation of Azurite Tempera
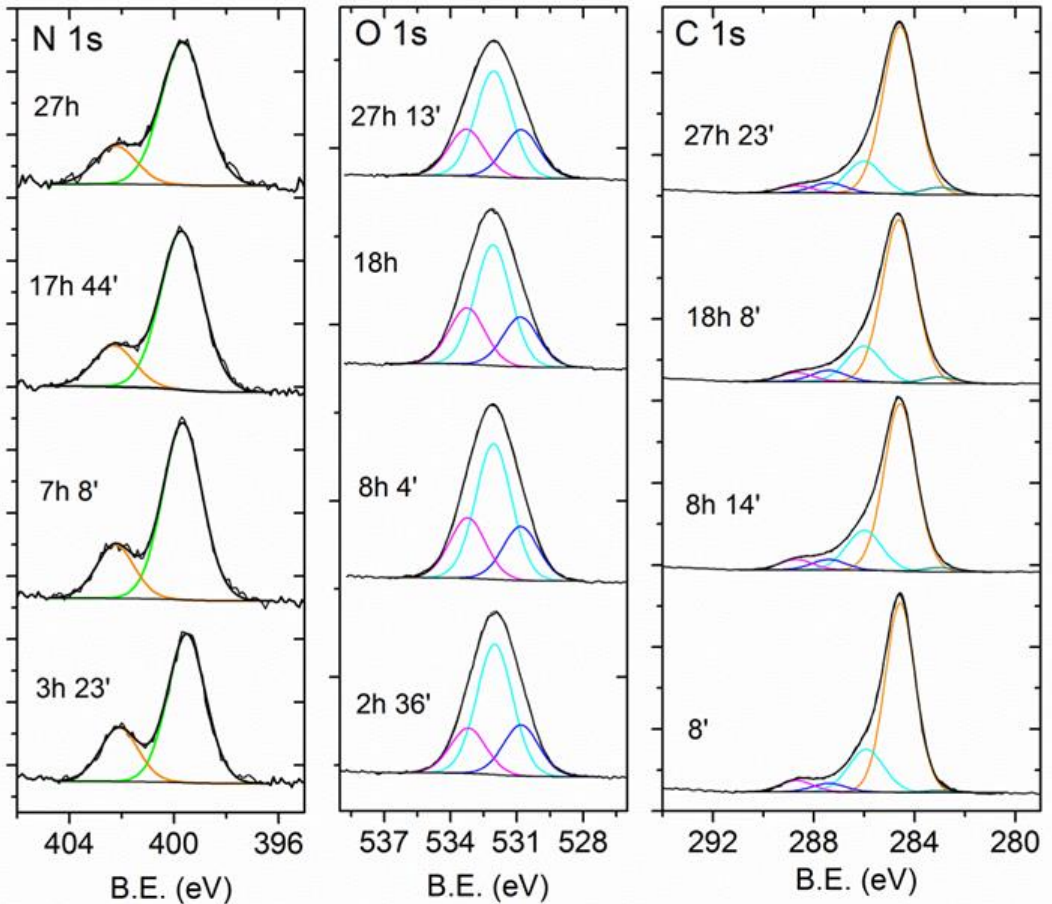

$\mathrm{Ar}^{+}$Irradiation of Azurite Tempera
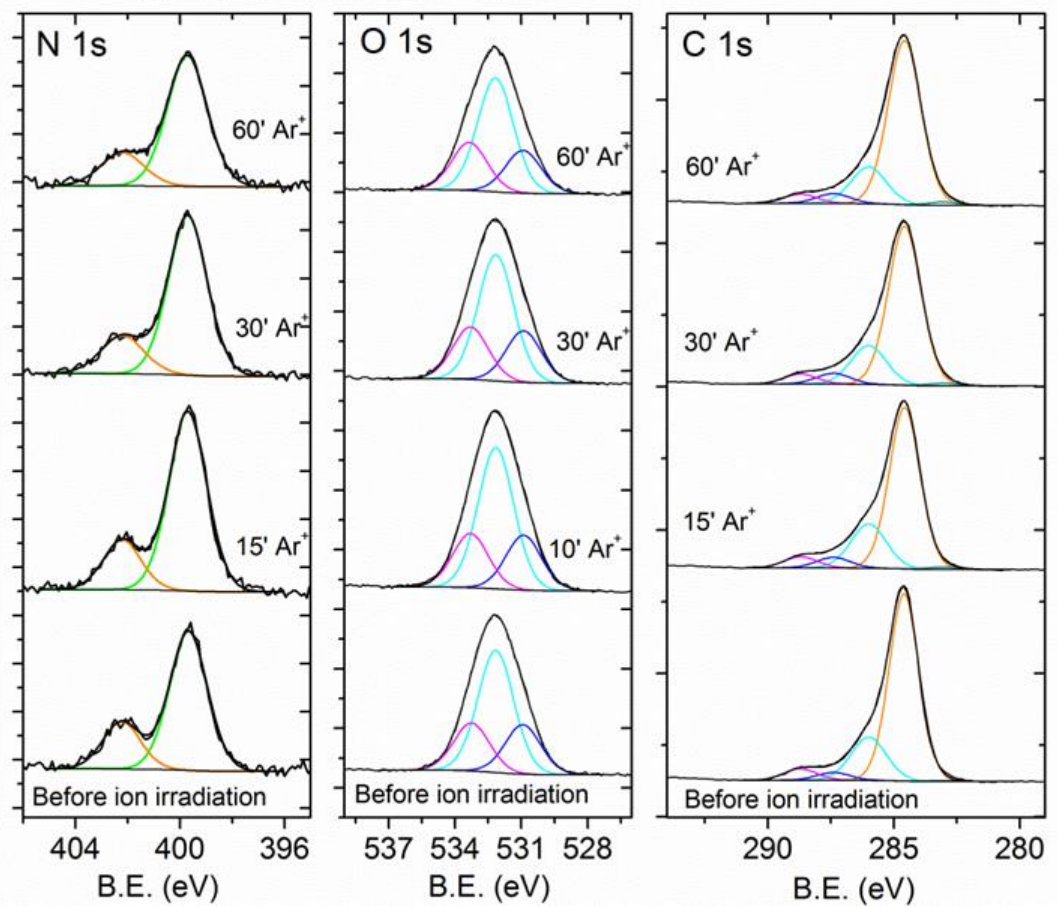